\title{
A CASE STUDY OF THE IRANIAN NATIONAL RAILWAY AND ITS ABSOLUTE CAPACITY EXPANSION USING ANALYTICAL MODELS
}

\author{
Bayan Bevrani, Robert L. Burdett, Prasad K. D. V. Yarlagadda \\ Queensland University of Technology, Brisbane, Australia
}

Submitted 24 September 2014; resubmitted 29 October 2014, 1 February 2015; accepted 20 April 2015; first published online 11 October 2015

\begin{abstract}
Identifying railway capacity is an important task that can identify 'in principal' whether the network can handle an intended traffic flow, and whether there is any free capacity left for additional train services. Capacity determination techniques can also be used to identify how best to improve an existing network, and at least cost. In this article, an optimization approach has been applied to a case study of the Iran national railway, in order to identify its current capacity and to optimally expand it given a variety of technical conditions. This railway is very important in Iran and will be upgraded extensively in the coming years. Hence, the conclusions in this article may help in that endeavor. A sensitivity analysis is recommended to evaluate a wider range of possible scenarios. Hence, more useful lower and upper bounds can be provided for the performance of the system.
\end{abstract}

Keywords: railway capacity; railway expansion; track duplication; analytical model; sensitivity analysis.

\section{Introduction}

\section{Background Information}

This paper considers the measurement and expansion of capacity in the National Rah Ahane Iran (RAI, Iranian Railways) railway network. A simplified version that only includes the main lines was selected for analysis. Some parts of the network were not included because those areas are less critical. The accurate quantification of railway capacity is of great importance, especially in a developing country such as Iran. According to the homepage of the Iranian Railways (IranRail 2014), Iran's railway network is being extended by approximately $500 \mathrm{~km}$ of new rail per year. This is one of the greatest growths of any railway network in the world currently. By 2015 it is expected that RAI will be expanded to include all regional population centres. At this stage, construction activities have been planned for the near future. The purpose of this paper is to help planners in Iran to determine absolute capacity of current and future railway infrastructure, and to assist expansion activities. The primary aim of this paper is also to analyze the application and expansion of the Burdett and Kozan (2006) absolute capacity determination model in the context of RAI railway network. The secondary objective is to perform a sensitivity analysis of different elements and parametric values of the model with an open mind to possible extensions and modifications. Other capacity models could be utilized to analyse the RAI network but that is outside the scope of this paper.

In this paper, capacity is viewed as the sum of the number of trains that traverse each corridor over a specified time. Railway capacity can be characterized in two different ways, namely absolute and actual capacity. Absolute capacity determines the 'maximum' capacity of a railway network. Absolute capacity is an ideal measure and does not consider the possibility of delays, i.e. on critical sections, from loading/unloading goods and passengers, maintenance, and possible collision conflicts of trains. Hence, absolute capacity does not necessarily determine the real capacity of railway network and it is a theoretical value. Actual capacity, however, does include delays and is a measure of the real capacity.

It should be noted that individual corridors can be analyzed separately, as if they were not part of a larger, more complex network. Similarly, the total capacity of all individual corridors may be compared to the capacity of the whole network, in order to identify negative interaction effects and congestion levels. Absolute capacity depends on the number and mix of trains that traverse each corridor. Corridors, however, consist of one or more sections and hence the possibility that the same section occurs in different corridors is a certainty in complex railway networks. These 'shared' sections can

Corresponding author: Robert L. Burdett

E-mail: r.burdett@qut.edu.au

Copyright @ 2015 Vilnius Gediminas Technical University (VGTU) Press

http://www.tandfonline.com/TRAN 
become bottlenecks on the network, and will affect the overall system capacity and the capacity of individual corridors.

Railway capacity is not a single unique number; it is dependent on the mix of trains and how they are used. Different train types can have substantially different operating characteristics, including maximum speed, power-to ton ratio, and dispatching priority. Hence, a capacity model can only be used to identify whether the infrastructure can support the future traffic load. The aim of capacity model is also to realize whether there is sufficient capacity in a network. An understanding of how the mix of trains (i.e. the traffic) interacts is necessary for efficient planning, and for the expansion of infrastructure that will provide additional capacity. Capacity determination is vital for the expansion of railway networks. It helps planners to decide where the most significant changes can be made, to increase accessibility and reliability and to increase the flow of freight and passenger trains in the best way.

The remainder of the paper is organized as follows. In the next sub-section recent and noteworthy research that considers railway capacity modelling and capacity expansion has been reviewed and discussed. In Section 1 analytical models for capacity determination and expansion were developed. The expansion model consists of two types, a static version and a time varying version. In Section 2 the case study is introduced for which the numerical investigations in Section 3 have been applied. Also in Section 3 various sensitivity analysis have been performed for the different model parameters. Finally, in last section this paper's conclusion and future research directions are summarized.

\section{Literature Review}

This section provides a review of the literature concerning capacity determination, capacity expansion, and railway planning. There is an abundance of research on capacity determination involving networks of various types. Examples include De Kort et al. (2003), Goverde et al. (2013), Landex (2009), Mussone et al. (2013), Burdett, Kozan (2004, 2006, 2014), Bevrani et al. (2015), Ferguson (2014). The integration, coordination, and planning of the different key components is typically concentrated upon. For instance, Burdett and Kozan (2004) discussed the details behind the application of timetabling trains in order to maximise and identify the capacity of a railway network. In that article, interference delays were ignored and this considerably reduced the complexity of the timetabling problem. Burdett and Kozan (2006) followed up their previous article from Burdett and Kozan (2004) and developed analytical capacity determination models. In particular they identified how the mix of different train types affects the absolute capacity of a railway network. The proposed mathematical optimization model takes into account the percentage mix of trains, the direction of travel, dwelling times, train speeds, and the presence and position of signals. Mussone et al. (2013) proposed an analytical capacity model for railway systems. That model was based upon the Burdett and Kozan (2006) model but it takes into account junctions and other more complex nodes and stations. It is also able to calculate the capacity of a railway system without decomposing the problem into sub problems.

The UIC method (UIC 2004) is a competing capacity approach that is based upon the compression of an existing timetable. Critical sections of rail are saturated in that approach, and the progress of trains over time is counted. A weakness of the UIC is that a timetable is always required and that timetable is never violated or altered. However, this is also an advantage because it also takes into account the way a particular railway system is actually used. In this article an existing timetable is not available; hence that method cannot be used.

The challenges of capacity allocation on a railway network was addressed by Gibson (2003). They have identified the key features of rail timetables and track access rights. They introduced three basic methodologies for allocating capacity on the rail network such as administered, cost-based, and market/value-base. Lusby et al. (2011) provided a broad overview of the different techniques for routing trains in railway networks in order to maximise capacity utilisation. In summary, solving these types of problems, result in large formulations. Furthermore, these approaches are inflexible because additional train paths cannot be included easily.

Sectional Running Time (SRT) is an important component that affects the capacity of railway network. Kozan and Burdett (2005), Vromans et al. (2006) and Harrod (2009) have shown that SRT has a significant impact on capacity analysis, for instance, a slight change in SRT can have remarkable effect on the amount of capacity.

The efficient use of assets to increase capacity has been considered for various types of systems. For railways Lai et al. (2010) is noteworthy. They suggested a capacity model to evaluate network capacity and to help planners by introducing possible expansion option to determine the optimal network investment. The model assumes the entire network is double tracked. They ignore meeting between trains and assume meeting occur within sections. In addition, the impacts and causes of heterogeneity with freight and passenger traffic are determined by using dispatch simulation software. The impact of different types of heterogeneity on implications for capacity planning had been studied to introduce more effective planning and efficient rail operations (Dingler et al. 2009). The paper of Shih et al. (2014) is also noteworthy because they compared different capacity expansion strategies for single track railway lines. For example, they considered the effect of placing additional sidings and the extension of existing sidings. They also considered track duplications in a limited way. This paper chose the best expansion strategy by performing an efficiency and reliability analyses using simulations.

For systems other than railways the recent article by Singh et al. (2012) is notable. They developed a generic mixed integer linear programming capacity expansion planning model to identify infrastructure improvements for optimising a bulk material supply chain. It was 
necessary to use meta-heuristics because that model was computationally intractable.

Some support tools have been introduced for capacity management. Krueger (1999) introduced a practical parametric capacity model to increase the efficiency of track movements. This model identified bottleneck areas, and other places where congestion occurs. Another decision support tool was introduced to allocate the capital investment toward determining the best possible way for optimal capacity planning (Lai, Barkan 2011). This decision support tool can determine the optimal investment plan by maximizing the return on investment from capacity expansion plans. Therefore, it will enhance the ability of stakeholders to provide reliable service to customers.

This article builds upon the analysis performed in Yaghini et al. (2014). In that paper the impact of different train types were investigated for the Tehran-Zanjan corridor in Iran. They found that capacity tends to increase nonlinearly and the mix of train types reduces the railway line capacity. In contrast, the entire Iranian network is considered in this article and capacity increase via infrastructure expansion.

\section{Analytical Model for Capacity Determination and Expansion}

As previously mentioned, absolute capacity is not a single unique number and varies for different mixes of trains. The capacity model deals with this by utilizing directional and proportional distributions that describe and regulate the percentage mix of trains on each corridor and in each direction. Both freight and passenger train services are included in the percentage mix. In complex networks there is high probability that a section will be part of several different corridors. These shared sections will be more saturated, i.e. heavily occupied. In this section the Burdett and Kozan (2006) model is utilized. That mathematical formulation has been simplified for this article and is as follows:

Maximize:

$$
A b s C a p=\sum_{c \in C i \in I} \sum_{i}\left(\vec{x}_{i}^{c}+\overleftarrow{x}_{i}^{c}\right),
$$

subject to:

$$
\begin{aligned}
& \sum_{i \in I}\left(\vec{y}_{i}^{s} \vec{T}_{i}^{s}+\overleftarrow{y}_{i}^{s} \overleftarrow{T}_{i}^{s}\right) \leq T \cdot \tau_{s}, \\
& \forall s \in S \text { [section saturation]; } \\
& \vec{x}_{i}^{c}+\overleftarrow{x}_{i}^{c}=\eta_{i}^{c} \sum_{j \in I}\left(\vec{x}_{j}^{c}+\grave{x}_{j}^{c}\right),
\end{aligned}
$$

$\forall i \in I, c \in C$ [proportional mix];

$\vec{x}_{i}^{c}=\mu_{i}^{c}\left(\vec{x}_{i}^{c}+\overleftarrow{x}_{i}^{c}\right)$,

$\forall i \in I, c \in C$ [directional mix];

$\sum_{i \in I}\left(\vec{x}_{i}^{c}+\grave{x}_{i}^{c}\right)=\sigma_{c} \sum_{c^{\prime} \in C} \sum_{i \in I}\left(\vec{x}_{i}^{c^{\prime}}+\overleftarrow{x}_{i}^{c^{\prime}}\right)$,

$\forall c \in C$ [mix across corridors];

$$
\begin{aligned}
& \vec{x}_{i}^{c}, \bar{x}_{i}^{c} \geq 0, \\
& \forall i \in I, c \in C \text { [positivity requirement]; }
\end{aligned}
$$$$
\vec{y}_{i}^{s}=\sum_{c \in C \mid s \in \Omega_{c}}\left(\vec{x}_{i}^{c}\right) \text { and }
$$

\begin{tabular}{|c|c|}
\hline \multicolumn{2}{|r|}{ Indices } \\
\hline$i, j, c, s, t$ & Train, train, corridor, section, time period \\
\hline \multicolumn{2}{|r|}{ Sets } \\
\hline$C, I, S$ & Set of corridors, train types, sections \\
\hline \multicolumn{2}{|r|}{ Decision Variables } \\
\hline$\vec{x}_{i}^{c}, \overleftarrow{x}_{i}^{c}$ & \# of trains, forwards/backwards on corridor $c$ \\
\hline$\vec{y}_{i}^{s}, \overleftarrow{y}_{i}^{s}$ & \# of trains, forwards/backwards on section $s$ \\
\hline \multicolumn{2}{|r|}{ Parameters } \\
\hline$T$ & Duration of time period for capacity analysis \\
\hline$\vec{T}_{i}^{s}, \stackrel{\leftarrow}{T}_{i}^{s}$ & $\begin{array}{l}\text { Section occupancy and SRT (can also include } \\
\text { delays and other factors to facilitate the } \\
\text { computation of actual capacity) }\end{array}$ \\
\hline$\mu_{i}^{c}, \eta_{i}^{c}, \sigma_{c}$ & $\begin{array}{l}\text { Directional and proportional train mix, } \\
\text { flow percentages across corridors }\end{array}$ \\
\hline$\Omega_{c}$ & Sections present in each corridor \\
\hline$\tau_{s}$ & Number of tracks on section $s$ \\
\hline
\end{tabular}$$
\overleftarrow{y}_{i}^{s}=\sum_{c \in C \mid s \in \Omega_{c}}\left(\overleftarrow{x}_{i}^{c}\right) \text { [section usage]. }
$$

The variables and parameters for this model are summarized in Table 1.

Table 1. Variables and parameters of the base capacity model

The objective of this model is to determine the number of trains that traverse all corridors, in both the forward and reverse direction, over specified time period $T$. Constraint (2) ensures that the flow through each section of the network must be less than or equal to the saturation limit. Constraint (3) ensures that the proportional mix of trains in each corridor is satisfied. Constraint (4) regulates the flow of trains in each direction. Similarly, constraint (5) regulates the flow of traffic between the different corridors. The last constraint ensures that the decision variables, i.e. the number of trains of each type traversing each corridor, are positive. It should be noted, that Eq. (7) is a mechanism to translate train numbers across different corridors to a compatible number across sections.

Constraint (5) regulates competition across corridors, however it is necessary, and perhaps more realistic, that competition must be regulated between specific corridors with common sections. Hence, in this article a new idea is put forth. For example, a new parameter $\sigma_{c}^{c, c^{\prime}}$ should be defined which describes the $\%$ of trains that should use corridor $c$ in comparison to the combined total that use corridor $c$ and $c^{\prime}$. Hence $\sigma_{c}^{c, c^{\prime}}+\sigma_{c^{\prime}}^{c, c^{\prime}}=1$ and the following constraint should be added:

$$
\sum_{i \in I}\left(\vec{x}_{i}^{c}+\overleftarrow{x}_{i}^{c}\right)=\sigma_{c, c^{\prime}} \sum_{i \in I}\left(\vec{x}_{i}^{c}+\overleftarrow{x}_{i}^{c}+\vec{x}_{i}^{c^{\prime}}+\overleftarrow{x}_{i}^{c^{\prime}}\right) .
$$


In order to expand network capacity, track duplication has been considered. For example, duplicating the number of tracks that occur between adjacent locations on the network can significantly increase the capacity of the rail network. Upon reflection it is easy to include track duplication in the capacity model by adding the following constraints:

$\sum_{i \in I}\left(\vec{y}_{i}^{s} \vec{T}_{i}^{s}+\overleftarrow{y}_{i}^{s} \overleftarrow{T}_{i}^{s}\right) \leq\left(\tau_{s}+\|_{s}\right) T$,

$\forall s \in S$ [section saturation];

$\sum_{s \in S}\left(C t_{s}^{\|} \cdot \|_{s}\right) \leq B$ [limitation on spending - budget];

$0 \leq\left\|_{s} \leq\right\|_{s}^{\max }, \forall s \in S$ [limit on track numbers];

$\sum_{s \in S}\left(\|_{s}\right) \leq N$ [limitation on number of duplications].

In the above modifications the number of parallel tracks added to each section is defined by $\|_{s}$. Also, the cost of a single duplicated track is $C t_{s}^{\|}$. The maximum number of tracks that can be added to section $\mathrm{s}$ is defined as $\|_{s}^{\max }$. Constraint (2) is replaced with constraint (9) as it includes the effect of track duplications on capacity. For example, in the normal situation where we have a single section of track, there is a total of $T$ units of time for trains to use that section. However, if we duplicate that section of rail, and assume that each track is completely independent, twice as many trains can traverse the same section and capacity can in theory be doubled. In total, there are hence $2 T$ units of time available. In general $\tau_{s}+\|_{s}$ is the total number of tracks available and a multiplier for the increase in capacity. The assumption of track independence within parallel sections is believed to be sufficient for high level planning purposes. Constraint (10) is added to enforce a specified limitation on the total budget (i.e. $B$ ) for duplicating tracks. Maximizing the capacity is still the objective function here. An assumption is also made for the SRTs to be the same on parallel tracks. This assumption must be made otherwise additional decisions concerning which parallel track individual trains are assigned to, are needed. From a practical perspective, track duplication cannot be separated from budgetary considerations. This is because the problem would become unbounded, and sections would be duplicated without limit. In the event that a budget is not provided it is necessary to restrict the number of duplications and to do this constraint (12) should be added. It can be viewed as an optional constraint and does not need to be added otherwise.

Another decision-making problem can also be formulated whereby the sections that should be upgraded in order to achieve a specified level of absolute capacity is to be determined. In that problem, a budget could be provided, but it is not entirely necessary. This variant problem has an alternative objective, which is cost minimization.

Capacity increases could be required over time. Time varying expansion model can be introduced to help planner to increase the capacity in certain period by considering the optimal cost and time. In order to identify a plan of capacity expansions over time the following model is formulated:

Minimize: $\hat{P}$,

subject to:

$\sum_{i \in I}\left(\vec{y}_{i, p}^{s} \vec{T}_{i}^{s}+\overleftarrow{y}_{i, p}^{s} \stackrel{\leftarrow}{T}_{i}^{s}\right) \leq T \cdot \tau_{s, p}$,

$\forall s \in S, \forall p \in P$ [section saturation];

$\vec{y}_{i, p}^{s}=\sum_{c \in C \mid s \in \Omega_{c}}\left(\vec{x}_{i, p}^{c}\right)$ and

$\overleftarrow{y}_{i, p}^{s}=\sum_{c \in C \mid s \in \Omega_{c}}\left(\overleftarrow{x}_{i, p}^{c}\right)$ [section usage];

$\vec{x}_{i, p}^{c}+\grave{x}_{i, p}^{c}=\eta_{i, p}^{c} \sum_{j \in I}\left(\vec{x}_{j, p}^{c}+\grave{x}_{j, p}^{c}\right)$,

$\forall i \in I, c \in C, \forall p \in P$ [proportional mix];

$\vec{x}_{i, p}^{c}=\mu_{i, p}^{c}\left(\vec{x}_{i, p}^{c}+\overleftarrow{x}_{i, p}^{c}\right)$,

$\forall i \in I, c \in C, \forall p \in P$ [directional mix];

$\sum_{i \in I}\left(\vec{x}_{i, p}^{c}+\bar{x}_{i, p}^{c}\right)=\sigma_{c} \sum_{c^{\prime} \in C} \sum_{i \in I}\left(\vec{x}_{i, p}^{c^{\prime}}+\bar{x}_{i, p}^{c^{\prime}}\right)$,

$\forall c \in C, \forall p \in P$ [mix across corridors];

$\vec{x}_{i, p}^{c}, \overleftarrow{x}_{i, p}^{c} \geq 0$,

$\forall i \in I, c \in C, \forall p \in P$ [positivity requirement];

$0 \leq\left\|_{s, p} \leq\right\|_{s}^{\max }, \tau_{s, p} \leq \|_{s}^{\max }$,

$\forall s \in S, p \in P$ [limit on track numbers];

$\tau_{s, p}=\tau_{s, p-1}, \tau_{s, p=} \tau_{s, p-1}+\|_{s, p-1}$,

$\forall s \in S, \forall p \in P \mid p>1$ [current track numbers];

$A_{p}=\sum_{c \in C i \in I} \sum_{i, p}\left(\vec{x}_{i, p}^{c}+\overleftarrow{x}_{i, p}^{c}\right) \geq \mathbb{A}_{p}$,

$\forall p \in P$ [intermediate requirement];

$e_{p}=\sum_{s \in S}\left(C t_{s, p}^{\|} \cdot \|_{s, p}\right)$,

$\forall p \in P$ [current expenditure];

$1 \leq \hat{P} \leq \bar{P}$ [bound on the period];

$\sum_{p=1 . . . n p} e_{p} \leq B_{p}, \forall p \in P$ [limit on spending];

$e_{p+1} \leq\left(1-\varphi_{p}\right) M^{+}$,

$\forall p \in P \mid p<P$ [no further spending];

$A_{p} \geq \varphi_{p} \cdot A_{f}, \forall p \in P$ [min requirement];

$A_{p} \geq A_{p-1}, \forall p \in P \mid p>1$ [increasing capacity];

$p<\hat{P}+\left(\varphi_{p}\right) M^{+}, \forall p \in P$ [binary condition];

$p \geq \hat{P}+\left(\varphi_{p}-1\right) M^{+}, \forall p \in P$ [binary condition];

$\varphi_{p} \in\{0,1\}, \forall p \in P$ [binary parameter]. 
The primary purpose of this model is to create an expansion plan of minimal duration $\hat{P}$. The output of this model is a list of which sections should be duplicated in each period of time. Furthermore, this model ensures that the capacity of the system has been increased to specified level. The decisions that are made are limited by the budget that has been provided. The parameters in this model are the same as previously defined above except that a subscript for the time period $p$ has been introduced. The planning period is limited. The duration of each period is for example one year however, any other suitable period of time could be selected. Half of the constraints, i.e. Eqs (13-19), have already been defined and these focus upon the determination of network capacity. The remaining constraints deal purely with the expansion decision.

Eq. (24) ensures that the total spending across all periods of time must be less than the specified budgetary limit. Eq. (28) ensures that the absolute capacity in each period is greater than the last period, i.e. it is strictly increasing. The model meets the specified minimum requirement $A_{f}$ for absolute capacity and furthermore that there will be no further spending after time period $\hat{P}$. The binary variable $\varphi_{p}$ has been introduced in order to identify whether each period $p$ for instance occurs before or after $\hat{P}$. For example if $p \geq \hat{P}$, then $\varphi_{p}=1$. Similarly if $p<\hat{P}$, then $\varphi_{p}=0$. This binary variable is used within the constraints 27,29 , and 30 . Constraint 29 and 30 describe the relationship between the index $p$, $\hat{P}$ and $\varphi_{p}$.

\section{Case Study Details}

This paper considers a simplified version of Iran's railway network that passes through Tehran and the ports in the south of Iran. RAI is the name of this national rail system. It links the population centres in the west and east of Iran, and has single and double tracks lines. Iran's most populated cities are close to the capital Tehran. Iran has a large population of about 80 million people, and constitutes a large area of land geographically. There is much travel by train from the west to the east of the country, between the different religious centres (i.e. cities). In addition, the main ports are located in the north and south, near to the sea, on the border of Iran. According to Tehran Times (2012), 33 million tons of goods and 29 million passengers are transported annually by this railway. In 2011, this network accounted for $9 \%$ and $11 \%$ of all transportations in Iran. Fig. 1 shows visually the main corridors where passengers and freight are transported and the networks data is shown in Appendix A. This network data was extracted from the official RAI railway network map. Unfortunately, this map is not entirely to scale. However, it is sufficiently close to real life values. More accurate values can be obtained from Jim Fergusson's Railway and Tramway Station Lists (Jim Fergusson's Railway... 2014), however, some inaccuracies exist in that information too, regarding the names and positions of railway station and other infrastructure which have been updated in recent years.

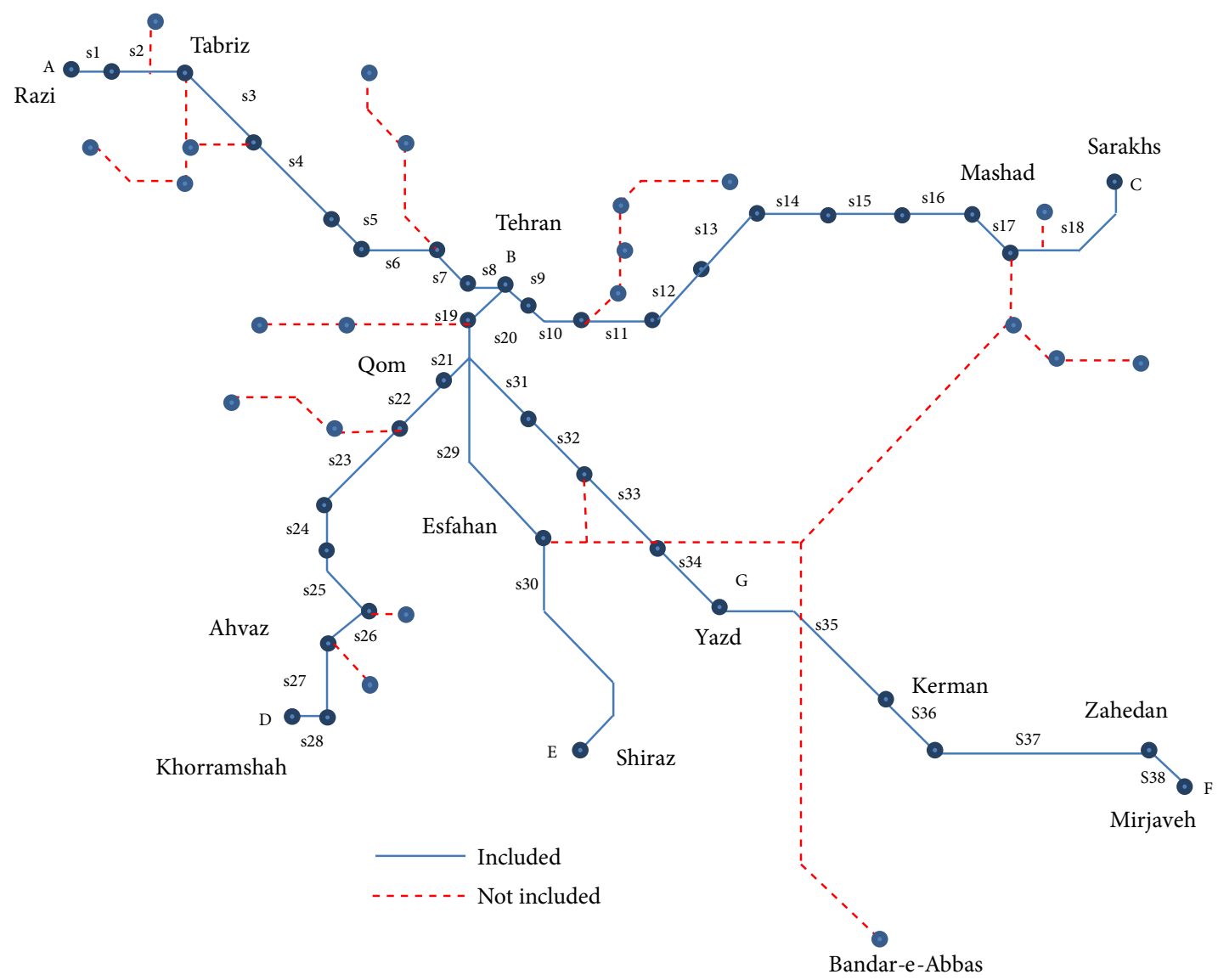

Fig. 1. Network diagram for the RAI 
This network has 38 sections and approximately 9 major corridors whose length varies from 1527-2724 km (Jim Fergusson's Railway... 2014). The Iranian rail network is the preferred mode of transport as the Iranian road network has been recognized as one of the most dangerous networks in the world, with many accidents per year (Khajehpour 2013). RAI has extensive infrastructure expansion plan/objectives to provide improved access and to meet future demands in developing population centres. Many new railway lines have been planned and will be constructed in near future. The cost of infrastructure expansion over the next 5 to 10 years will be billions of dollars.

\section{Numerical Investigations}

\subsection{Sensitivity Analysis of Capacity}

In this section a sensitivity analysis has been performed. In that analysis the model has been applied (i.e. solved) many times. It is important to note that three train types were considered whose speeds are 80, 100 and $120 \mathrm{~km} / \mathrm{h}$ respectively. The analysis was also performed for a time period of one day, i.e. 1440 minutes. For three train types, and assuming increments of 0.01 (i.e. $1 \%$ ), there are $C_{100}^{102}=\frac{102 \cdot 101}{2}=5151$ possible ways of changing $\eta^{c}$ if $\eta_{1}^{c}+\eta_{2}^{c}+\eta_{3}^{c}=1$. If there were only two train types then the actual number of possibilities reduces considerably, i.e. to a value of 101 . In general, the actual number is given by the following formula $C_{N}^{N+|I|-1}=\frac{(N+|I|-1) !}{(|I|-1) !(N) !}$, where $N=100$ and $|I|$ is the number of train types. This formula and other related ones have been discussed in Burdett and Kozan (2003). It should also be noted that $\eta_{i}^{c}=0$ is allowed here. This formula is derived by realizing that there are 100 values that can be assigned to the $|I|$ groups plus $|I|-1$ values of zero percent are possible.

In summary, the number of possible proportional distributions is very large and it is impractical to evaluate each one, i.e. by solving the optimization model, although it is possible to do so. The question of what to do with all of these results and what they mean then arises. In conclusion, it is best to take an alternative strategy. In this article, we propose that individual corridors and individual train types are analyzed. The proportional distribution and the percentage flow parameters can easily be altered to facilitate this. These results are shown in
Tables 2 and 3. These restrictions were then discarded and multiple train types were considered as was the capacity of the entire network. The duplication of the entire network was also investigated. In the Tables 2 and 3 'Mix' refers to an arbitrarily selected mix of trains, which is shown in Appendix B.

In Table 2 the results for train type 1 can be viewed as lower bounds on capacity, for instance for individual corridors and for the whole network, as that train is slowest. Furthermore, train type 3 results can be viewed as upper bounds, because it is fastest. Any proportional mix of trains must result in a value of capacity between the aforementioned limits.

The utilization value (and the associated value of reduction) in the last column describes the relationship between the networks capacity as a whole with the total capacity of all the individual corridors together. Hence, in this example, approximately one third of that sum is achieved. This means that the structure of the network does not allow individual corridors to be utilized fully and in isolation. In other words, they must share the networks lines with trains from other corridors. This is clearly obvious from Fig. 1. The extent of the interaction effects is quite high for the specified mix of trains. If the corridors were defined in different ways, then the utilization and reduction values could be used to make a comparison with other alternatives.

\subsection{Manual Duplication}

Track duplications are considered in this section. Table 3 shows that duplicating all sections do not change the extent of the interaction effects, except for the case where a proportional mix of trains was selected. If the results in Table 3 were divided by those in Table 2 then the ratio is approximately 2 for all cases. Hence, it can be concluded that if capacity is to be doubled then in theory an additional track could be built in each section parallel to the existing one.

Duplicating all sections of rail is however quite extreme and costly. Hence, it would be best to duplicate fewer sections if possible, but still obtain comparable levels of capacity if not the same level. Therefore, the bottleneck sections on each serial link have been duplicated first and the model have been re-solved to see what effect occurs. This course of action was taken because of existing theory on bottlenecks. For example, it is the bottleneck section that dictates the capacity of a single line and altering other sections is superfluous until issues on that section are resolved. For example, in the RAI network, there are six separate linear segments. In

Table 2 . Sensitivity analysis of absolute capacity per $\mathrm{km}$

\begin{tabular}{|l|c|c|c|c|c|c|c|c|c|c|c|c|}
\hline \multirow{2}{*}{$i$} & \multirow{2}{*}{$\begin{array}{c}\mathbb{1} \\
(\mathrm{n} e t)\end{array}$} & \multicolumn{10}{|c|}{$\mathbb{A}$ (individual corridors) } & \multirow{2}{*}{ Utilisation (reduction) } \\
\cline { 3 - 13 } & 1 & 2 & 3 & 4 & 5 & 6 & 7 & 8 & 9 & Sum & \\
\hline 1 (LB) & 16.41 & 6.8571 & 8.7273 & 3.3684 & 4.2667 & 6.8571 & 3.3684 & 4.2667 & 3.3864 & 4.2667 & 45.3648 & $0.36(0.64)$ \\
\hline 2 & 20.512 & 8.7514 & 10.9091 & 4.2105 & 5.3333 & 8.5714 & 4.2105 & 5.3333 & 4.2105 & 5.3333 & 56.8633 & $0.36(0.64)$ \\
\hline $3(\mathrm{UB})$ & 24.615 & 10.286 & 13.091 & 5.0526 & 6.40 & 10.286 & 5.0526 & 6.40 & 5.0526 & 6.40 & 68.0208 & $0.36(0.64)$ \\
\hline Mix & 20.955 & 9.4538 & 10.515 & 3.4655 & 4.3986 & 8.2484 & 3.8365 & 5.8824 & 4.0583 & 4.3896 & 54.2481 & $0.39(0.61)$ \\
\hline
\end{tabular}


each of those, the following sections are longest: $s 4, s 18$, $s 19, s 23, s 30, s 37$. These bottleneck sections were duplicated and resulting absolute values are shown in Table 4. Fig. 2 shows the changes to the network.

The values in Table 4 lie between those in Tables 2-3.

For some corridors, larger improvements have occurred, but in others, there has been less. To identify the exact difference, the ratios of the values in Table 5 with those in Table 2 and 3 have been computed (i.e. individually). Upon closer inspection, the reason for the presence or absence of improvement is purely based upon the distribution of the section lengths in each linear segment. In some segments, the duplication of the bottle- neck has shifted the bottleneck outside of that linear segment to another part of network, whereas in other cases the bottleneck still occurs within the linear segment. Table 5 shows that duplicating the bottleneck sections in each linear segment can increase capacity by approximately 1 to 1.3 times. However, the values in Table 3 are still somewhat higher than those in Table 4, i.e. 1.5 to 1.91 times greater. Hence, some other sections still need to be duplicated in order to obtain those higher levels of capacity.

Given the aforementioned success at increasing capacity by duplicating the bottleneck sections, the next logical step is to duplicate the next set of bottleneck sections on each linear segment. In other words, we pro-

Table 3. Duplication of all sections with an additional single track

\begin{tabular}{|l|c|c|c|c|c|c|c|c|c|c|c|c|}
\hline \multirow{2}{*}{$i$} & \multirow{2}{*}{$\begin{array}{c}\mathbb{1} \\
(\mathrm{net})\end{array}$} & \multicolumn{10}{|c|}{$\mathbb{A}$ (individual corridors) } & \multirow{2}{*}{ Utilisation (reduction) } \\
\cline { 3 - 13 } & & 1 & 2 & 3 & 4 & 5 & 6 & 7 & 8 & 9 & Sum & \\
\hline $1(\mathrm{LB})$ & 32.82 & 13.714 & 17.455 & 6.737 & 8.5333 & 13.714 & 6.737 & 8.5333 & 6.737 & 8.5333 & 90.6939 & $0.36(0.64)$ \\
\hline 2 & 41.024 & 17.143 & 21.818 & 8.4211 & 10.667 & 17.143 & 8.4211 & 10.667 & 8.4211 & 10.667 & 113.368 & $0.36(0.64)$ \\
\hline $3(\mathrm{UB})$ & 49.229 & 20.571 & 26.182 & 10.105 & 12.80 & 20.571 & 10.105 & 12.80 & 10.105 & 12.80 & 136.039 & $0.36(0.64)$ \\
\hline Mix & 41.909 & 18.908 & 21.03 & 6.931 & 8.797 & 16.497 & 7.673 & 11.765 & 8.1167 & 8.7791 & 108.497 & $0.39(0.61)$ \\
\hline
\end{tabular}

Table 4. Sensitivity analysis of duplicated bottleneck sections

\begin{tabular}{|c|c|c|c|c|c|c|c|c|c|c|c|c|}
\hline \multirow{2}{*}{$i$} & \multirow{2}{*}{$\begin{array}{c}\mathbb{A} \\
\text { (net) }\end{array}$} & \multicolumn{10}{|c|}{$\mathbb{A}$ (individual corridors) } & \multirow{2}{*}{ Utilisation (reduction) } \\
\hline & & 1 & 2 & 3 & 4 & 5 & 6 & 7 & 8 & 9 & Sum & \\
\hline $1(\mathrm{LB})$ & 21.839 & 9.143 & 9.143 & 4.364 & 4.571 & 12.80 & 4.364 & 4.571 & 4.364 & 4.571 & 57.891 & $0.38(0.62)$ \\
\hline 2 & 27.299 & 11.429 & 11.429 & 5.455 & 5.714 & 16.00 & 5.455 & 5.714 & 5.455 & 5.714 & 72.365 & $0.38(0.62)$ \\
\hline 3 (UB) & 32.758 & 13.714 & 13.714 & 6.546 & 6.857 & 19.20 & 6.546 & 6.8571 & 6.546 & 6.857 & 86.837 & $0.38(0.62)$ \\
\hline Mix & 27.876 & 12.605 & 11.015 & 4.489 & 4.713 & 15.397 & 4.97 & 6.303 & 5.257 & 4.703 & 69.452 & $0.40(0.60)$ \\
\hline
\end{tabular}

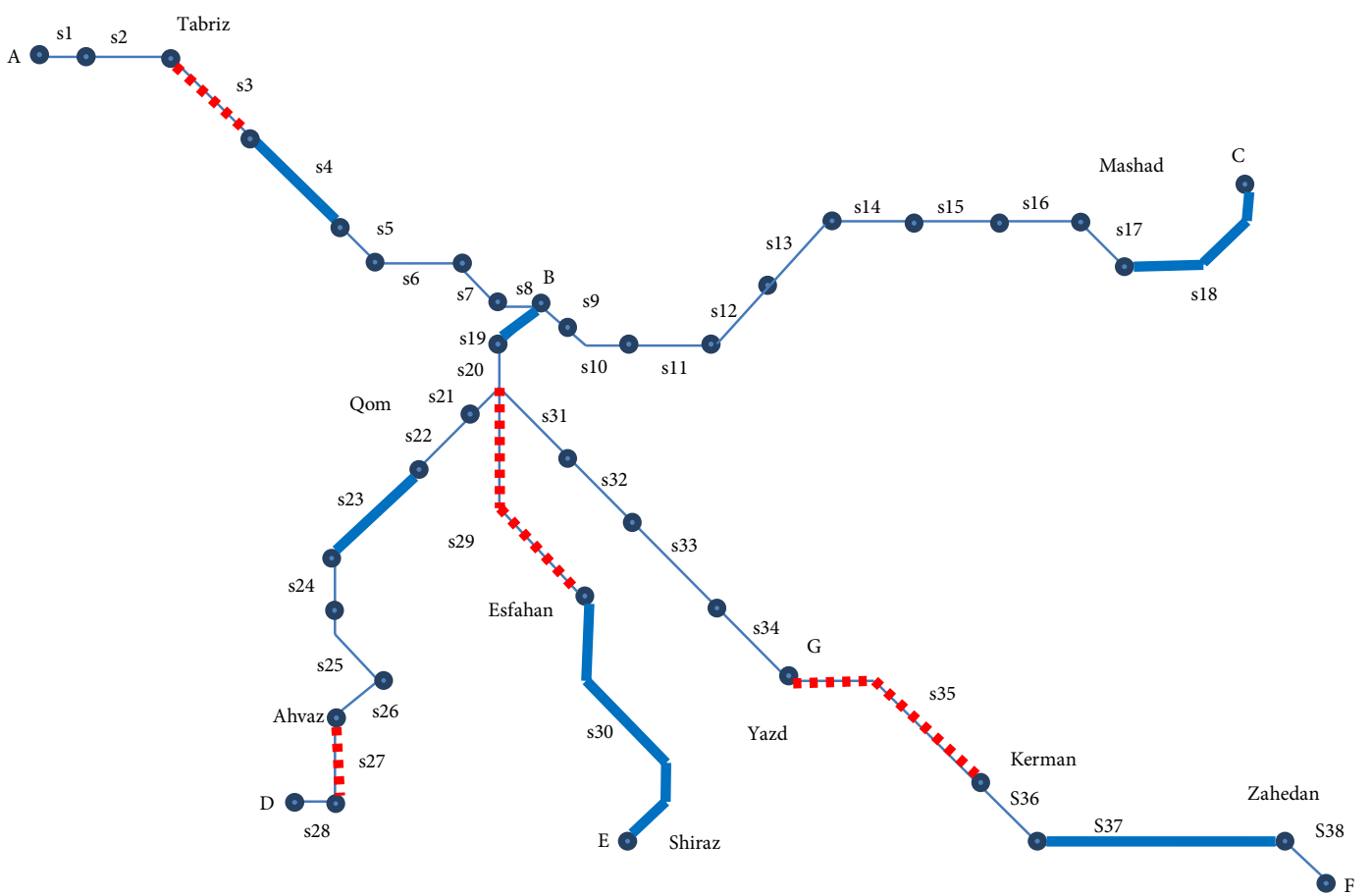

Fig. 2. Upgraded network diagram for the RAI (bold - duplicated, dashed - next longest section) 
pose an iterative process of track duplications in order to increase capacity. Those sections are $s 3, s 27, s 29$ and $s 35$. The model was resolved and the results are shown in Table 7.

The values in Table 7 lie between those in Tables 3-4. For some corridors, larger improvements have occurred, and in some of them the capacity is exactly equal. To identify the exact difference, the ratios of the values in Table 7 with those in Tables 3-4 have been computed (i.e. individually).

Tables 8-9 show that the latest set of duplications has increased capacity by approximately 1 to 1.87 times. Furthermore, the values in Table 3 are quite close to the values that are shown in Table 7 . Some further duplication is warranted in order to reach the capacity values in Table 3 but it is difficult to identify with certainty where sections should be duplicated. Hence, a mathematical model that identifies these positions would be highly beneficial.

\subsection{Automated Duplication}

In this section we have taken the basic capacity model and have added the aforementioned modifications for expanding capacity via track duplications. The model has been applied to the case study and the results are presented in Table 10. In Table 10 when the restriction of a single duplication (i.e. $\|_{s}^{\max }=1$ ) per section is enforced, the absolute capacity cannot be increased beyond 41.909 trains. Upon inspection, the reason for this is that in order to increase capacity further the same sections should be duplicated again whereas the other unduplicated sections should not. When the restriction of a single duplication per section is relaxed to two then the absolute capacity does increase. In comparison, the increase is quite significant because the capacity changes from 41.909 to 60.819 trains. After 46 track duplications, absolute capacity does not increase any further. In the third column when the maximum duplication is 3 , this

Table 5. Ratio of Table 3 to Table 2

\begin{tabular}{|c|c|c|c|c|c|c|c|c|c|c|c|}
\hline \multirow{2}{*}{$i$} & \multirow{2}{*}{$\begin{array}{c}\mathbb{A} \\
\text { (net) }\end{array}$} & \multicolumn{10}{|c|}{$\mathbb{A}$ (individual corridors) } \\
\hline & & 1 & 2 & 3 & 4 & 5 & 6 & 7 & 8 & 9 & Sum \\
\hline $1(\mathrm{LB})$ & 1.33 & 1.33 & 1.05 & 1.3 & 1.07 & 1.87 & 1.3 & 1.07 & 1.29 & 1.07 & 1.28 \\
\hline 2 & 1.33 & 1.31 & 1.05 & 1.3 & 1.07 & 1.87 & 1.3 & 1.07 & 1.3 & 1.07 & 1.27 \\
\hline $3(\mathrm{UB})$ & 1.33 & 1.33 & 1.05 & 1.3 & 1.07 & 1.87 & 1.3 & 1.07 & 1.3 & 1.07 & 1.28 \\
\hline Mix & 1.33 & 1.33 & 1.05 & 1.3 & 1.07 & 1.87 & 1.3 & 1.07 & 1.3 & 1.07 & 1.28 \\
\hline
\end{tabular}

Table 6. Ratio of Table 2 to Table 3

\begin{tabular}{|c|c|c|c|c|c|c|c|c|c|c|c|}
\hline \multirow{2}{*}{$i$} & \multirow{2}{*}{$\begin{array}{c}\mathbb{A} \\
\text { (net) }\end{array}$} & \multicolumn{10}{|c|}{$\mathbb{A}$ (individual corridors) } \\
\hline & & 1 & 2 & 3 & 4 & 5 & 6 & 7 & 8 & 9 & Sum \\
\hline $1(\mathrm{LB})$ & 1.5 & 1.5 & 1.91 & 1.54 & 1.87 & 1.07 & 1.54 & 1.87 & 1.54 & 1.87 & 1.57 \\
\hline 2 & 1.5 & 1.5 & 1.91 & 1.54 & 1.87 & 1.07 & 1.54 & 1.87 & 1.54 & 1.87 & 1.57 \\
\hline 3 (UB) & 1.5 & 1.5 & 1.91 & 1.54 & 1.87 & 1.07 & 1.54 & 1.87 & 1.54 & 1.87 & 1.57 \\
\hline Mix & 1.5 & 1.5 & 1.91 & 1.54 & 1.87 & 1.07 & 1.54 & 1.87 & 1.54 & 1.87 & 1.56 \\
\hline
\end{tabular}

Table 7. Sensitivity analysis of further duplicated bottleneck sections

\begin{tabular}{|c|c|c|c|c|c|c|c|c|c|c|c|c|}
\hline \multirow{2}{*}{$i$} & \multirow{2}{*}{$\begin{array}{c}\mathbb{A} \\
\text { (net) }\end{array}$} & \multicolumn{10}{|c|}{$\mathbb{A}$ (individual corridors) } & \multirow{2}{*}{ Utilisation (reduction) } \\
\hline & & 1 & 2 & 3 & 4 & 5 & 6 & 7 & 8 & 9 & Sum & \\
\hline $1(\mathrm{LB})$ & 25.945 & 10.105 & 10.105 & 6.737 & 8.533 & 12.80 & 6.737 & 8.5333 & 6.737 & 8.5333 & 78.821 & $0.33(0.67)$ \\
\hline 2 & 32.431 & 12.632 & 12.632 & 8.421 & 10.667 & 16.00 & 8.421 & 10.667 & 8.421 & 10.667 & 98.528 & $0.33(0.67)$ \\
\hline 3 (UB) & 38.917 & 15.158 & 15.158 & 10.105 & 12.80 & 19.20 & 10.105 & 12.80 & 10.105 & 12.80 & 118.231 & $0.33(0.67)$ \\
\hline Mix & 33.384 & 13.932 & 12.715 & 69.31 & 8.797 & 15.397 & 7.673 & 11.765 & 8.1167 & 8.7791 & 94.106 & $0.35(0.65)$ \\
\hline
\end{tabular}

Table 8 . Ratio of Table 7 to Table 4

\begin{tabular}{|c|c|c|c|c|c|c|c|c|c|c|c|}
\hline \multirow{2}{*}{$i$} & \multirow{2}{*}{$\begin{array}{c}\mathbb{A} \\
\text { (net) }\end{array}$} & \multicolumn{10}{|c|}{$\mathbb{A}$ (individual corridors) } \\
\hline & & 1 & 2 & 3 & 4 & 5 & 6 & 7 & 8 & 9 & Sum \\
\hline $1(\mathrm{LB})$ & 1.19 & 1.11 & 1.11 & 1.54 & 1.87 & 1.00 & 1.54 & 1.87 & 1.54 & 1.87 & 1.36 \\
\hline 2 & 1.19 & 1.11 & 1.11 & 1.54 & 1.87 & 1.00 & 1.54 & 1.87 & 1.54 & 1.87 & 1.36 \\
\hline 3 (UB) & 1.19 & 1.11 & 1.11 & 1.54 & 1.87 & 1.00 & 1.54 & 1.87 & 1.54 & 1.87 & 1.36 \\
\hline Mix & 1.20 & 1.11 & 1.15 & 1.54 & 1.87 & 1.00 & 1.54 & 1.87 & 1.54 & 1.87 & 1.35 \\
\hline
\end{tabular}


Table 9. Ratio of Table 3 to Table 7

\begin{tabular}{|c|c|c|c|c|c|c|c|c|c|c|c|}
\hline \multirow{2}{*}{$i$} & \multirow{2}{*}{$\begin{array}{c}\mathbb{A} \\
\text { (net) }\end{array}$} & \multicolumn{10}{|c|}{$\mathbb{A}$ (individual corridors) } \\
\hline & & 1 & 2 & 3 & 4 & 5 & 6 & 7 & 8 & 9 & Sum \\
\hline $1(\mathrm{LB})$ & 1.26 & 1.36 & 1.73 & 1.00 & 1.00 & 1.07 & 1.00 & 1.00 & 1.00 & 1.00 & 1.15 \\
\hline 2 & 1.26 & 1.36 & 1.73 & 1.00 & 1.00 & 1.07 & 1.00 & 1.00 & 1.00 & 1.00 & 1.15 \\
\hline $3(\mathrm{UB})$ & 1.26 & 1.36 & 1.73 & 1.00 & 1.00 & 1.07 & 1.00 & 1.00 & 1.00 & 1.00 & 1.15 \\
\hline Mix & 1.26 & 1.36 & 1.65 & 1.00 & 1.00 & 1.07 & 1.00 & 1.00 & 1.00 & 1.00 & 1.15 \\
\hline
\end{tabular}

Table 10. Result of expansion model (no flow constraint)

\begin{tabular}{|c|c|c|c|c|c|c|c|c|c|c|c|}
\hline \multicolumn{4}{|c|}{$\|_{s}^{\max }=1$} & \multicolumn{4}{|c|}{$\|_{s}^{\max }=2$} & \multicolumn{4}{|c|}{\|\|$_{s}^{\max }=3$} \\
\hline$\#$ & $\mathbb{A}$ & $\#$ & $\mathbb{A}$ & $\#$ & $\mathbb{A}$ & $\#$ & $\mathbb{A}$ & $\#$ & $\mathbb{A}$ & $\#$ & $\mathbb{A}$ \\
\hline 0 & 20.955 & 20 & 41.361 & 0 & 20955 & 20 & 48.03 & 0 & 20.955 & 20 & 49.187 \\
\hline 1 & 25.046 & 21 & 41.909 & 1 & 25.046 & 21 & 48.86 .1 & 1 & 25.046 & 21 & 49.90 \\
\hline 2 & 26.692 & & & 2 & 26.692 & 22 & 49.91 .6 & 2 & 26.692 & 22 & 50.663 \\
\hline 3 & 27.991 & & & 3 & 27.991 & 23 & 50.95 .3 & 3 & 27.991 & 23 & 51.763 \\
\hline 4 & 29.356 & & & 4 & 29.356 & 24 & 52.05 & 4 & 29.356 & 24 & 52.487 \\
\hline 5 & 30.60 & & & 5 & 30.60 & 25 & 52.761 & 5 & 30.60 & 25 & 53.587 \\
\hline 6 & 32.716 & & & 6 & 32.716 & 26 & 53.075 & 6 & 32.716 & 26 & 54.30 \\
\hline 7 & 33.319 & & & 7 & 33.319 & 27 & 53.075 & 7 & 33.319 & 27 & 54.98 \\
\hline 8 & 34.724 & & & 8 & 34.724 & 28 & 53.706 & 8 & 34.724 & 28 & 55.554 \\
\hline 9 & 35.324 & & & 9 & 35.568 & 29 & 54.225 & 9 & 35.568 & 29 & 57.218 \\
\hline 10 & 36.741 & & & 10 & 36.741 & 30 & 55.039 & 10 & 36.741 & 30 & 58.033 \\
\hline 11 & 37.306 & & & 11 & 37.767 & 31 & 56.112 & 11 & 37.817 & 31 & 58.711 \\
\hline 12 & 38.162 & & & 12 & 38.478 & 32 & 57.056 & 12 & 38.478 & 32 & 60.603 \\
\hline 13 & 38.955 & & & 13 & 39.709 & 33 & 57.867 & 13 & 40.016 & 33 & 61.051 \\
\hline 14 & 40.605 & & & 14 & 40.892 & 34 & 58.811 & 14 & 40.892 & 34 & 62.841 \\
\hline 15 & 41.153 & & & 15 & 42.441 & 35 & 59.232 & 15 & 42.441 & 35 & 63.621 \\
\hline 16 & 41.153 & & & 16 & 43513 & 36 & 59.232 & 16 & 43.513 & 36 & 64.334 \\
\hline 17 & 41.153 & & & 17 & 45.011 & 37 & 59.808 & 17 & 45.837 & 37 & 64.755 \\
\hline 18 & 41.153 & & & 18 & 46.083 & 38 & 60.819 & 18 & 46.617 & 38 & 66.511 \\
\hline 19 & 41.153 & & & 19 & 46.898 & & & 19 & 48.288 & & \\
\hline
\end{tabular}

allows the absolute capacity to be increased even further. These increases stop after 66 tracks duplication; and capacity does not increase from additional duplications. The increase in capacity for incremental changes to the total number of duplications is not uniform. Furthermore, some incremental changes do not result in an increase to capacity. Sometimes multiple duplications must be performed in order for the absolute capacity to be increased.

In the manual approach, we assumed that duplicating bottleneck sections is the best way to increase the capacity. However, Table 10 shows that capacity can be increased further by choosing different sections. For example, for the specified mix of trains the manual approach was able to increase capacity to 27.876 trains while the expansion model was able to increase it to 32.716 trains. This is a significant increase.

The results in Table 10 have different flows on each corridor. The model has chosen different flows each time in order to maximize capacity for the current set of restrictions. This means that the model has been biased towards different corridors as supposed to other ones (Fig. 3). Hence, some corridors have not been given any flow at all; in practice, this is unacceptable. Consequently, minimum flows should be defined for each corridor and the analysis must be re-performed. This is not to say that the results in Table 10 are of no value. These results provide an upper bound of the effect of duplication and provide higher levels of capacity than would have been obtained otherwise. 


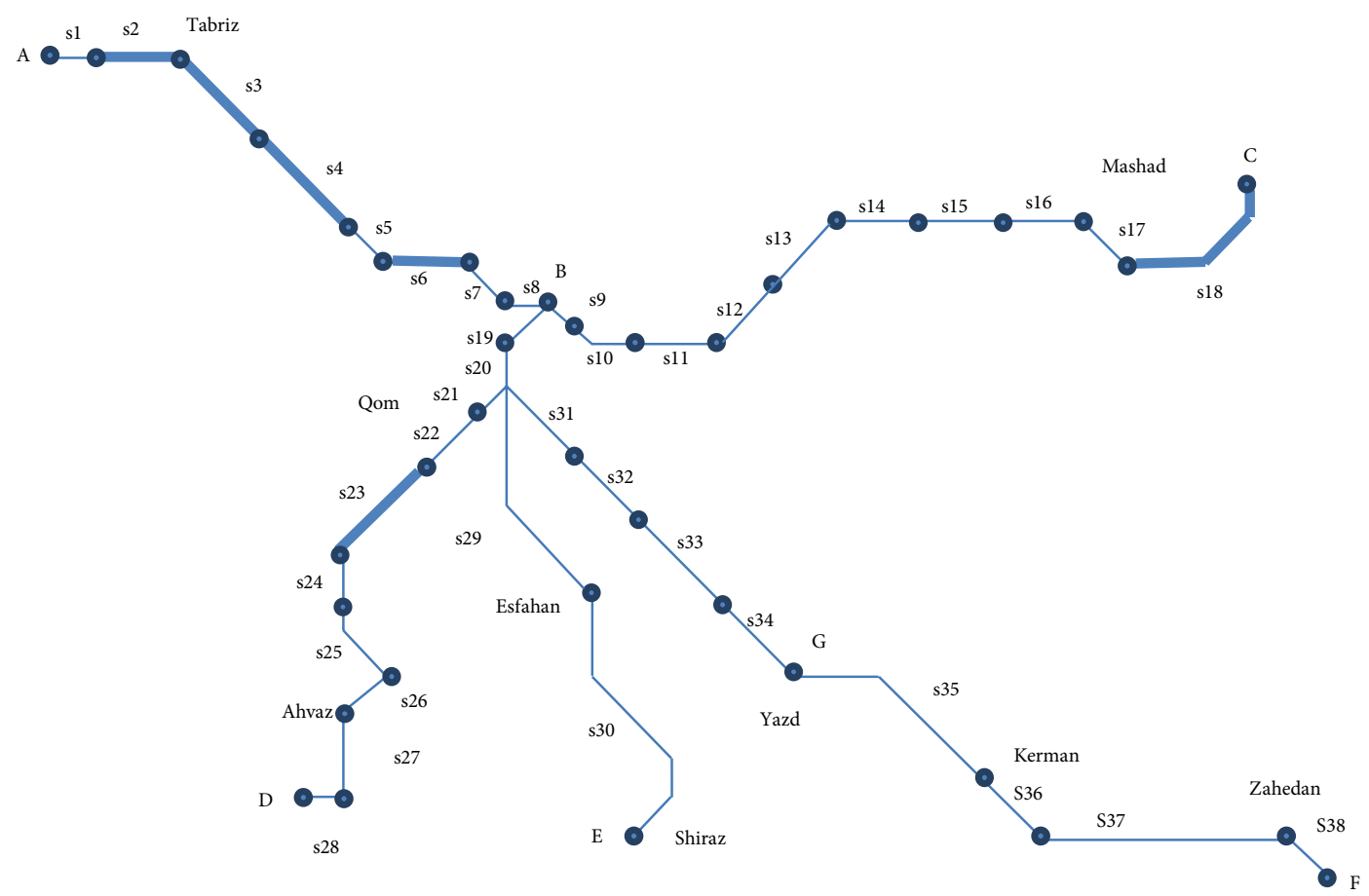

Fig. 3. Expanded network (unequal flow)

When there is no restriction on corridor flows, the model maximizes capacity by giving preference to corridors that have a higher capacity. This is clearly shown in Fig. 4 because none of the lines are flat, i.e. each line varies and the percentages are vastly different between corridors. There is no special pattern to the assignment of flow to different corridors.

In Table 11, the percentage flow for each corridor is assumed equal. Duplicating the specific sections shown in Fig. 5 allows a greater flow of trains. In some linear segments, two sections were duplicated while some linear segment was not duplicated at all. Due to the imbalance in the lengths of the different sections within different corridors, this is clearly necessary. For example, some of the biggest sections were duplicated in the corridor A-E in order to be able to compete with the flow of other linear segments like A-C. These results are not immediately obvious or transparent. Hence, choosing correct sections for duplication can be quite difficult.

The sensitivity analysis in the preceding tables was based upon the incremental change to the number of track duplications. However, it is necessary to investigate incremental changes to the budget. The model was run again for the two different percentage flows. For instance, the percentage flow was not included initially, and then it was introduced so that the flow is the same

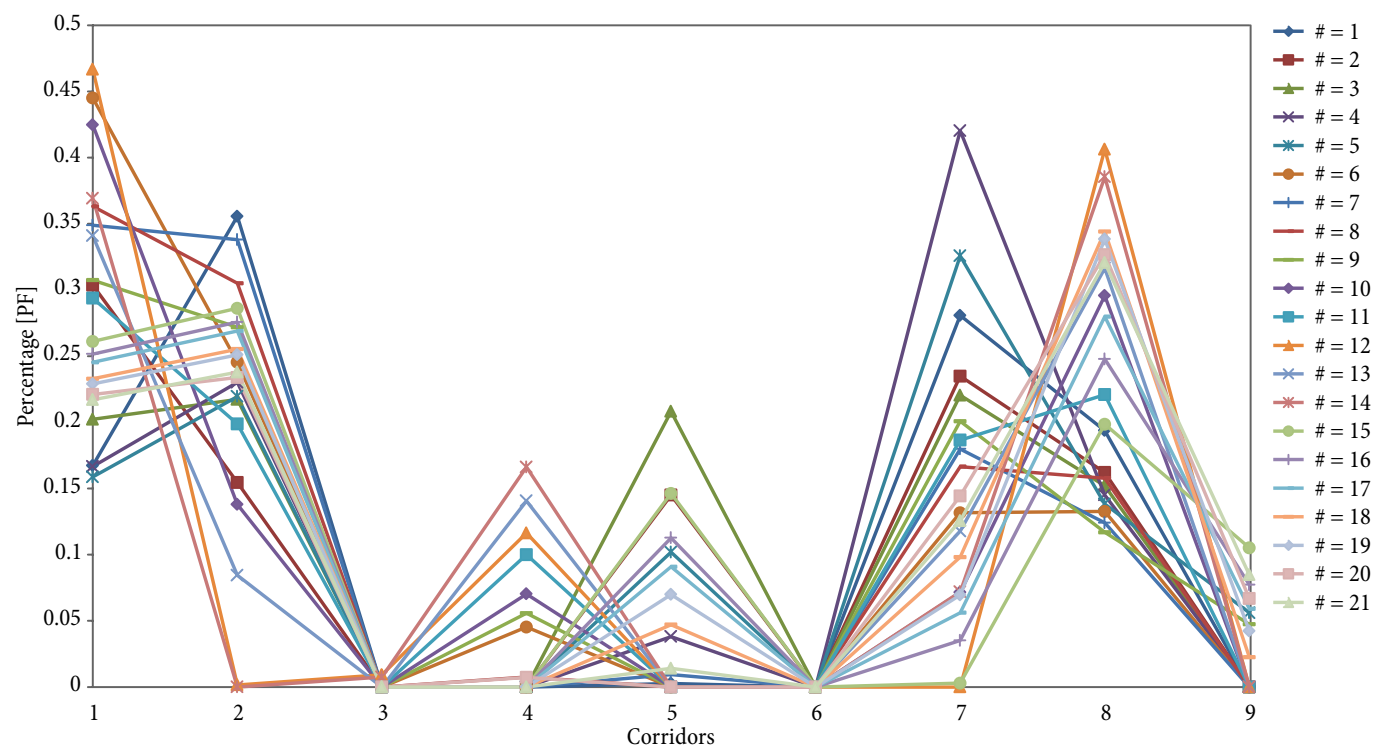

Fig. 4. Comparison of percentage flow on each corridor for different number of track duplications 
Table 11. Expansion results when flow is equal across all the corridors (i.e. $P F=1 / 9$ )

\begin{tabular}{|c|c|c|c|c|c|c|c|}
\hline \multicolumn{2}{|c|}{\|\|$_{s}^{\max }=1$} & \multicolumn{2}{|c|}{$\|_{s}^{\max }=2$} & \multicolumn{4}{|c|}{$\|_{s}^{\max }=3$} \\
\hline \# & $\mathbb{A}$ & $\#$ & $\mathbb{A}$ & \# & $\mathbb{A}$ & \# & $\mathbb{A}$ \\
\hline 0 & 11.3232 & 0 & 11.3232 & 0 & 11.3232 & 19 & 35.5844 \\
\hline 1 & 14.3637 & 1 & 14.3637 & 1 & 14.3637 & 20 & 35.5844 \\
\hline 2 & 14.6687 & 2 & 14.6687 & 2 & 14.6687 & 21 & 36.4922 \\
\hline 3 & 15.3896 & 3 & 15.3896 & 3 & 15.3896 & 22 & 36.4922 \\
\hline 4 & 19.5494 & 4 & 19.5494 & 4 & 19.5494 & 23 & 36.4922 \\
\hline 5 & 22.4812 & 5 & 22.4812 & 5 & 22.4812 & 24 & 36.4922 \\
\hline 6 & 22.6464 & 6 & 22.6464 & 6 & 22.6464 & 25 & 36.4922 \\
\hline & & 7 & 23.5517 & 7 & 23.5517 & 26 & 36.4922 \\
\hline & & 8 & 24.9091 & 8 & 24.9091 & 27 & 39.0988 \\
\hline & & 9 & 25.555 & 9 & 25.555 & 28 & 39.1736 \\
\hline & & 10 & 26.0308 & 10 & 26.0308 & 29 & 41.5151 \\
\hline & & 11 & 28.7273 & 11 & 28.7273 & 30 & 43.091 \\
\hline & & 12 & 29.3373 & 12 & 29.3373 & 31 & 43.091 \\
\hline & & 13 & 30.7793 & 13 & 30.7793 & 32 & 43.091 \\
\hline & & 14 & 30.7793 & 14 & 30.7793 & 33 & 44.006 \\
\hline & & 15 & 30.7793 & 15 & 30.7793 & 34 & 44.9623 \\
\hline & & 16 & 32.9724 & 16 & 32.9724 & 35 & 45.2927 \\
\hline & & 17 & 33.2121 & 17 & 33.2121 & & \\
\hline & & 18 & 33.9696 & 18 & 33.9696 & & \\
\hline
\end{tabular}

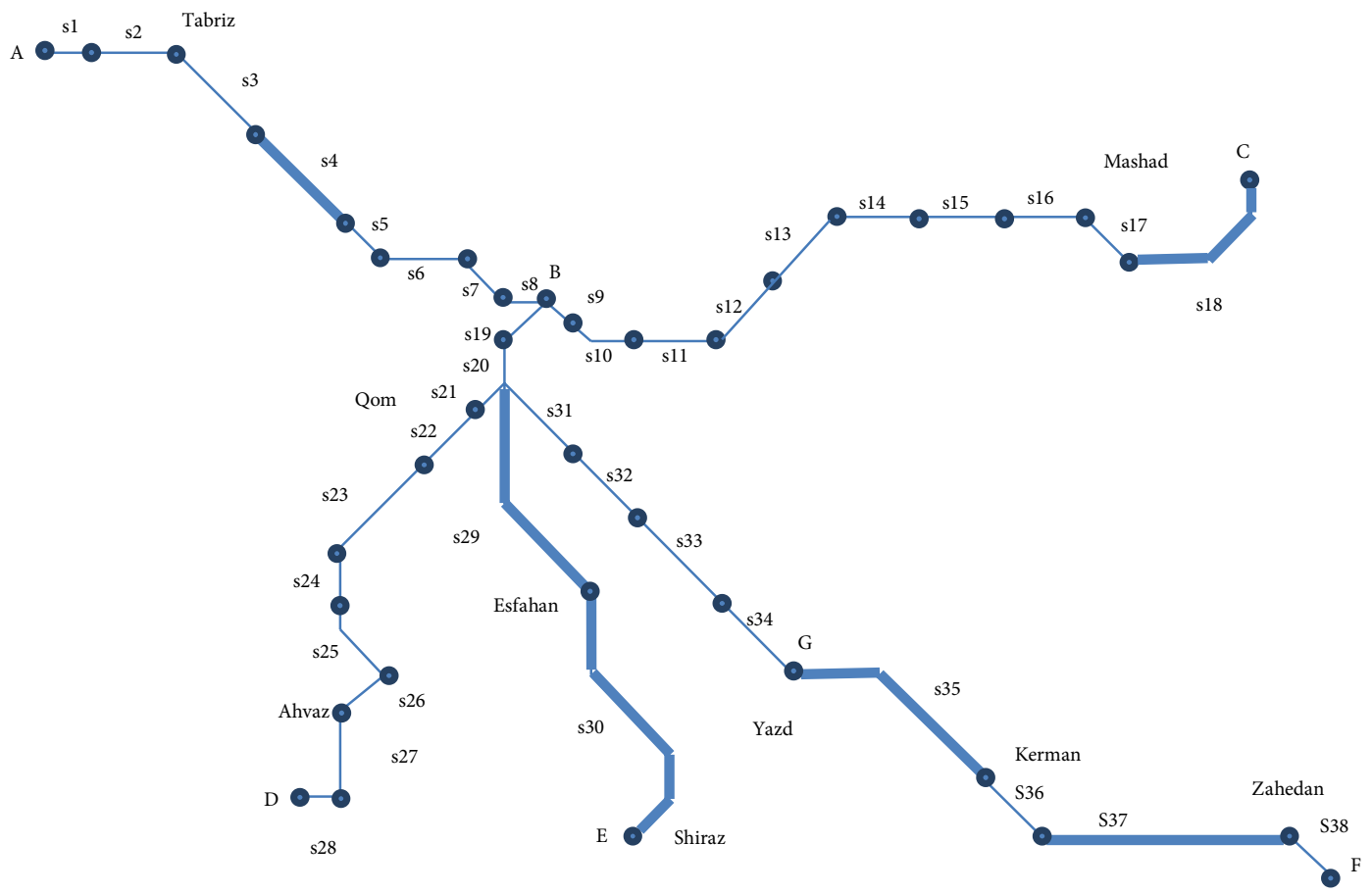

Fig. 5. Expanded network (equal flow)

on each corridor. The results for different limits of the number of duplications in each section were also analysed. The results are shown in Tables 12-15 and these are also summarised graphically in Fig. 6. The model was run 200 times. However, the tables are truncated to the point where no further change occurred.
The curves in Fig. 6 taper off and become flat and do not increase without limit. In the first chart (Fig. 6a), the increase is quite shallow. In the second chart (Fig. 6b), the increase is greater, but in the third (Fig. 6c), it is greatest when the duplication limit is most relaxed. 
Table 12. Absolute capacity for incremental budget changes $\left(\|_{s}^{\max }=1\right)$

\begin{tabular}{|c|c|c|c|c|c|c|c|c|c|}
\hline \multicolumn{6}{|c|}{ No $\%$ flow restriction } & \multicolumn{4}{|c|}{ Equal \% flow } \\
\hline$\#$ & $\mathbb{A}$ & $\#$ & $\mathbb{A}$ & $\#$ & $\mathbb{A}$ & $\#$ & $\mathbb{A}$ & $\#$ & $\mathbb{A}$ \\
\hline 0 & 20.9546 & 21 & 36.0093 & 42 & 41.1532 & 0 & 11.3232 & 21 & 19.5494 \\
\hline 1 & 20.9546 & 22 & 36.0093 & 43 & 41.1532 & 1 & 11.3232 & 22 & 22.4812 \\
\hline 2 & 22.6011 & 23 & 36.0093 & 44 & 41.1532 & 2 & 113232 & 23 & 22.4812 \\
\hline 3 & 25.0455 & 24 & 36.3149 & 45 & 41.1532 & 3 & 11.3232 & 24 & 22.6464 \\
\hline 4 & 25.0455 & 25 & 36.6963 & 46 & 41.3612 & 4 & 11.3232 & 25 & 22.6464 \\
\hline 5 & 26.692 & 26 & 36.6963 & 47 & 41.3612 & 5 & 11.3232 & 26 & 22.6464 \\
\hline 6 & 26.692 & 27 & 38.1102 & 48 & 41.9092 & 6 & 14.3637 & 27 & 22.6464 \\
\hline 7 & 27.1624 & 28 & 38.9546 & & & 7 & 14.3637 & 28 & 22.6464 \\
\hline 8 & 27.1624 & 29 & 38.9546 & & & 8 & 14.3637 & 29 & 22.6464 \\
\hline 9 & 27.8569 & 30 & 38.9546 & & & 9 & 14.3637 & 30 & 22.6464 \\
\hline 10 & 28.151 & 31 & 38.9546 & & & 10 & 14.3637 & 31 & 22.6464 \\
\hline 11 & 30.5997 & 32 & 38.9546 & & & 11 & 14.6687 & 32 & 22.6464 \\
\hline 12 & 30.5997 & 33 & 38.9546 & & & 12 & 14.6687 & 33 & 22.6464 \\
\hline 13 & 32.7164 & 34 & 39.6416 & & & 13 & 14.6687 & 34 & 22.6464 \\
\hline 14 & 33.1869 & 35 & 39.6416 & & & 14 & 14.6687 & 35 & 22.6464 \\
\hline 15 & 33.1869 & 36 & 39.6416 & & & 15 & 15.3896 & 36 & 22.6464 \\
\hline 16 & 33.1869 & 37 & 40.6051 & & & 16 & 15.3896 & 37 & 22.6464 \\
\hline 17 & 34.1755 & 38 & 40.6051 & & & 17 & 15.3896 & 38 & 22.6464 \\
\hline 18 & 35.5403 & 39 & 41.1532 & & & 18 & 15.3896 & 39 & 22.6464 \\
\hline 19 & 35.5403 & 40 & 41.1532 & & & 19 & 19.5494 & 40 & 22.6464 \\
\hline 20 & 36.0093 & 41 & 41.1532 & & & 20 & 19.5494 & 41 & 22.6464 \\
\hline
\end{tabular}

Table 13. Absolute capacity for incrementasl budget changes $\left(\|\|_{s}^{\max }=2\right)$

\begin{tabular}{|c|c|c|c|c|c|c|c|c|c|c|c|c|c|c|c|}
\hline \multicolumn{10}{|c|}{ No $\%$ flow restriction } & \multicolumn{6}{|c|}{ Equal \% flow } \\
\hline$\#$ & $\mathbb{A}$ & $\#$ & $\mathbb{A}$ & $\#$ & $\mathbb{A}$ & $\#$ & $\mathbb{A}$ & $\#$ & $\mathbb{A}$ & $\#$ & $\mathbb{A}$ & $\#$ & $\mathbb{A}$ & $\#$ & $\mathbb{A}$ \\
\hline 0 & 20.9546 & 21 & 37.0044 & 42 & 48.5423 & 63 & 55.2681 & 84 & 59.9377 & 0 & 11.3232 & 21 & 19.5494 & 42 & 29.3373 \\
\hline 1 & 20.9546 & 22 & 37.0044 & 43 & 48.8112 & 64 & 55.5452 & 85 & 60.4469 & 1 & 11.3232 & 22 & 22.4812 & 43 & 29.3373 \\
\hline 2 & 22.6011 & 23 & 39.3022 & 44 & 49.3307 & 65 & 56.328 & 86 & 60.6326 & 2 & 11.3232 & 23 & 22.4812 & 44 & 29.3373 \\
\hline 3 & 25.0455 & 24 & 40.164 & 45 & 50.2747 & 66 & 56.4861 & 87 & 60.8054 & 3 & 11.3232 & 24 & 22.6464 & 45 & 29.3373 \\
\hline 4 & 25.0455 & 25 & 40.2431 & 46 & 51.1365 & 67 & 56.7296 & 88 & 61.0343 & 4 & 11.3232 & 25 & 22.6464 & 46 & 30.7793 \\
\hline 5 & 26.692 & 26 & 40.7378 & 47 & 51.2155 & 68 & 56.8877 & 89 & 61.0343 & 5 & 11.3232 & 26 & 22.6464 & 47 & 30.7793 \\
\hline 6 & 26.692 & 27 & 40.9472 & 48 & 51.2155 & 69 & 57.0986 & 90 & 61.4311 & 6 & 14.3637 & 27 & 22.6464 & 48 & 30.7793 \\
\hline 7 & 27.1624 & 28 & 41.4162 & 49 & 51.6172 & 70 & 57.0986 & 91 & 61.6168 & 7 & 14.3637 & 28 & 226464 & 49 & 30.7793 \\
\hline 8 & 27.1624 & 29 & 41.4479 & 50 & 51.7214 & 71 & 57.8601 & 92 & 61.731 & 8 & 14.3637 & 29 & 22.6464 & 50 & 30.7793 \\
\hline 9 & 27.8569 & 30 & 42.5299 & 51 & 51.9071 & 72 & 57.8601 & 93 & 62.1044 & 9 & 14.3637 & 30 & 23.5517 & 51 & 30.7793 \\
\hline 10 & 28.151 & 31 & 44.9251 & 52 & 52.123 & 73 & 582617 & 94 & 62.2901 & 10 & 14.3637 & 31 & 23.5517 & 52 & 30.7793 \\
\hline 11 & 30.5997 & 32 & 45.7868 & 53 & 52.3087 & 74 & 58.4621 & 95 & 62.4622 & 11 & 14.6687 & 32 & 24.9091 & 53 & 30.7793 \\
\hline 12 & 30.5997 & 33 & 45.8659 & 54 & 53.1121 & 75 & 58.8113 & 96 & 62.6917 & 12 & 14.6687 & 33 & 24.9091 & 54 & 30.7793 \\
\hline 13 & 32.7164 & 34 & 45.8659 & 55 & 53.7063 & 76 & 58.8113 & 97 & 62.6917 & 13 & 14.6687 & 34 & 25.555 & 55 & 32.9724 \\
\hline 14 & 33.1869 & 35 & 46.2675 & 56 & 53.892 & 77 & 58.9673 & 98 & 62.8639 & 14 & 14.6687 & 35 & 26.0308 & 56 & 33.2121 \\
\hline 15 & 33.2341 & 36 & 46.3718 & 57 & 54.1608 & 78 & 59.2129 & 99 & 62.8639 & 15 & 15.3896 & 36 & 26.0308 & 57 & 33.2121 \\
\hline 16 & 33.2341 & 37 & 46.5575 & 58 & 54.2936 & 79 & 59.5169 & 100 & 62.8639 & 16 & 15.3896 & 37 & 28.7273 & 58 & 33.9696 \\
\hline 17 & 34.1755 & 38 & 46.7734 & 59 & 54.5625 & 80 & 59.5169 & 101 & 62.8639 & 17 & 15.3896 & 38 & 28.7273 & 59 & 33.9696 \\
\hline 18 & 35.5403 & 39 & 46.9591 & 60 & 54.5625 & 81 & 59.9186 & 102 & 62.8639 & 18 & 15.38 .96 & 39 & 28.7273 & 60 & 33.9696 \\
\hline 19 & 355403 & 40 & 47.7624 & 61 & 54.8665 & 82 & 59.9186 & 103 & 62.8639 & 19 & 19.5494 & 40 & 28.7273 & 61 & 33.9696 \\
\hline 20 & 36.0093 & 41 & 48.3567 & 62 & 54.9148 & 83 & 59.9186 & 104 & 62.8639 & 20 & 19.5494 & 41 & 28.7273 & 62 & 33.9696 \\
\hline
\end{tabular}


Table 14. Absolute capacity for incremental budget changes $\left(\|_{s}^{\max }=3\right)$

\begin{tabular}{|c|c|c|c|c|c|c|c|c|c|c|c|c|c|}
\hline \multicolumn{14}{|c|}{ No $\%$ flow restriction } \\
\hline$\#$ & $\mathbb{A}$ & $\#$ & $\mathbb{A}$ & \# & $\mathbb{A}$ & $\#$ & $\mathbb{A}$ & $\#$ & $\mathbb{A}$ & $\#$ & $\mathbb{A}$ & $\#$ & $\mathbb{A}$ \\
\hline 0 & 20.9546 & 21 & 37.0044 & 42 & 51.8871 & 63 & 61.7947 & 84 & 70.895 & 105 & 76.4049 & 106 & 80.7936 \\
\hline 1 & 20.9546 & 22 & 37.0044 & 43 & 51.8871 & 64 & 62.9739 & 85 & 71.0807 & 106 & 76.4049 & 107 & 80.9792 \\
\hline 2 & 22.6011 & 23 & 39.3022 & 44 & 51.8871 & 65 & 63.2866 & 86 & 72.0187 & 107 & 76.8257 & 108 & 82.109 \\
\hline 3 & 25.0455 & 24 & 40.164 & 45 & 52.6328 & 66 & 65.3661 & 87 & 72.0187 & 108 & 76.8257 & 109 & 82.109 \\
\hline 4 & 25.0455 & 25 & 40.2431 & 46 & 52.8185 & 67 & 65.3661 & 88 & 72.0187 & 109 & 77.0992 & 110 & 82.109 \\
\hline 5 & 26.692 & 26 & 40.7378 & 47 & 53.0769 & 68 & 66.7481 & 89 & 72.0187 & 110 & 77.2849 & 111 & 82.109 \\
\hline 6 & 26.692 & 27 & 40.9472 & 48 & 54.3484 & 69 & 66.7481 & 90 & 72.4442 & 111 & 77.6636 & 112 & 82.109 \\
\hline 7 & 27.1624 & 28 & 41.4162 & 49 & 55.4694 & 70 & 66.7481 & 91 & 72.6299 & 112 & 77.6636 & 113 & 82.3063 \\
\hline 8 & 27.1624 & 29 & 41.4479 & 50 & 56.555 & 71 & 66.7481 & 92 & 73.4563 & 113 & 77.7094 & 114 & 82.3063 \\
\hline 9 & 27.8569 & 30 & 42.5299 & 51 & 57.937 & 72 & 66.9585 & 93 & 73.4563 & 114 & 77.9093 & 115 & 82.3063 \\
\hline 10 & 28.151 & 31 & 44.9251 & 52 & 57.937 & 73 & 67.4351 & 94 & 73.4596 & 115 & 78.5959 & 116 & 82.4245 \\
\hline 11 & 30.5997 & 32 & 45.7868 & 53 & 57.937 & 74 & 68.2733 & 95 & 73.7024 & 116 & 78.5959 & 117 & 83.5542 \\
\hline 12 & 30.5997 & 33 & 45.8659 & 54 & 57.937 & 75 & 68.459 & 96 & 73.7024 & 117 & 79.3502 & 118 & 83.5542 \\
\hline 13 & 32.7164 & 34 & 45.8659 & 55 & 58.1473 & 76 & 69.6934 & 97 & 74.3439 & 118 & 79.3502 & 119 & 83.5542 \\
\hline 14 & 33.1869 & 35 & 46.2675 & 56 & 58.1473 & 77 & 69.6934 & 98 & 74.3439 & 119 & 79.3502 & 120 & 83.5542 \\
\hline 15 & 33.2341 & 36 & 46.3718 & 57 & 60.1623 & 78 & 69.6934 & 99 & 74.3439 & 120 & 79.3502 & 121 & 83.5542 \\
\hline 16 & 33.2341 & 37 & 47.0491 & 58 & 61.0241 & 79 & 69.6934 & 100 & 75.8404 & 121 & 79.6144 & 122 & 83.8185 \\
\hline 17 & 34.1755 & 38 & 48.1804 & 59 & 61.1032 & 80 & 69.6934 & 101 & 76.0261 & 122 & 79.6144 & 123 & 83.8185 \\
\hline 18 & 35.5403 & 39 & 48.5056 & 60 & 61.1032 & 81 & 70.1142 & 102 & 76.4049 & 123 & 80.1418 & 124 & 83.8185 \\
\hline 19 & 35.5403 & 40 & 50.6266 & 61 & 61.1032 & 82 & 70.3804 & 103 & 76.4049 & 124 & 80.2345 & 125 & 83.8185 \\
\hline 20 & 36.0093 & 41 & 50.6266 & 62 & 61.7947 & 83 & 70.4474 & 104 & 76.4049 & 125 & 80.2345 & 126 & 83.8185 \\
\hline
\end{tabular}

Table 15. Absolute capacity for incremental budget changes $\left(\|\|_{s}^{\max }=3\right)$

\begin{tabular}{|c|c|c|c|c|c|c|c|c|c|c|c|c|c|}
\hline \multicolumn{10}{|c|}{ Equal $P F$} \\
\hline$\#$ & $\mathbb{A}$ & $\#$ & $\mathbb{A}$ & $\#$ & $\mathbb{A}$ & $\#$ & $\mathbb{A}$ & $\#$ & $\mathbb{A}$ & $\#$ & $\mathbb{A}$ & $\#$ & $\mathbb{A}$ \\
\hline 0 & 11.3232 & 16 & 15.3896 & 32 & 24.9091 & 48 & 30.7793 & 64 & 35.5844 & 80 & 41.5151 & 96 & 45.2927 \\
\hline 1 & 11.3232 & 17 & 15.3896 & 33 & 24.9091 & 49 & 30.7793 & 65 & 35.5844 & 81 & 43091 & 97 & 45.2927 \\
\hline 2 & 11.3232 & 18 & 15.3896 & 34 & 25.555 & 50 & 30.7793 & 66 & 36.4922 & 82 & 43.091 & 98 & 45.2927 \\
\hline 3 & 11.3232 & 19 & 19.5494 & 35 & 26.0308 & 51 & 30.7793 & 67 & 36.4922 & 83 & 43.09 .1 & 99 & 45.2927 \\
\hline 4 & 11.3232 & 20 & 19.5494 & 36 & 26.0308 & 52 & 30.7793 & 68 & 36.4922 & 84 & 43.091 & 100 & 45.2927 \\
\hline 5 & 11.3232 & 21 & 19.5494 & 37 & 28.7273 & 53 & 30.7793 & 69 & 36.4922 & 85 & 43.091 & 101 & 45.2927 \\
\hline 6 & 14.3637 & 22 & 22.4812 & 38 & 28.7273 & 54 & 30.7793 & 70 & 36.4922 & 86 & 43.091 & 102 & 45.2927 \\
\hline 7 & 14.3637 & 23 & 22.4812 & 39 & 28.7273 & 55 & 32.9724 & 71 & 36.4922 & 87 & 43.091 & 103 & 45.2927 \\
\hline 8 & 14.367 & 24 & 226464 & 40 & 28.7273 & 56 & 33.2121 & 72 & 36.4922 & 88 & 44.006 & 104 & 45.2927 \\
\hline 9 & 14.3637 & 25 & 22.6464 & 41 & 287273 & 57 & 33.2121 & 73 & 36.4922 & 89 & 44.006 & \\
\hline 10 & 14.3637 & 26 & 22.6464 & 42 & 29.3373 & 58 & 33.9696 & 74 & 36.4922 & 90 & 44.006 & \\
\hline 11 & 14.6687 & 27 & 22.6464 & 43 & 29.3373 & 59 & 33.9696 & 75 & 39.0988 & 91 & 44.006 & \\
\hline 12 & 14.6687 & 28 & 22.6464 & 44 & 29.3373 & 60 & 33.9696 & 76 & 39.0988 & 92 & 44.006 & \\
\hline 13 & 14.6687 & 29 & 22.6464 & 45 & 29.3373 & 61 & 33.9696 & 77 & 39.0988 & 93 & 44.9623 \\
\hline 14 & 14.6687 & 30 & 23.5517 & 46 & 30.7793 & 62 & 33.9696 & 78 & 39.1736 & 94 & 44.9623 \\
\hline 15 & 15.3896 & 31 & 23.5517 & 47 & 30.7793 & 63 & 35.5844 & 79 & 39.1736 & 95 & 45.2927 &
\end{tabular}

Fig. 7 also shows the results for different track duplication limits in each section for both equal percentage flow (i.e. Fig. 7a) and no restriction on percentage flow (i.e. Fig. 7b). It should be noted that in Fig. $7 \mathrm{~b}$ the mo- del bypasses bottleneck issues but in contrast the model cannot bypass the bottleneck issues in Fig. $7 \mathrm{a}$. This is clearly demonstrated by the branching of the lines and the common parts that occur beforehand. 
a)

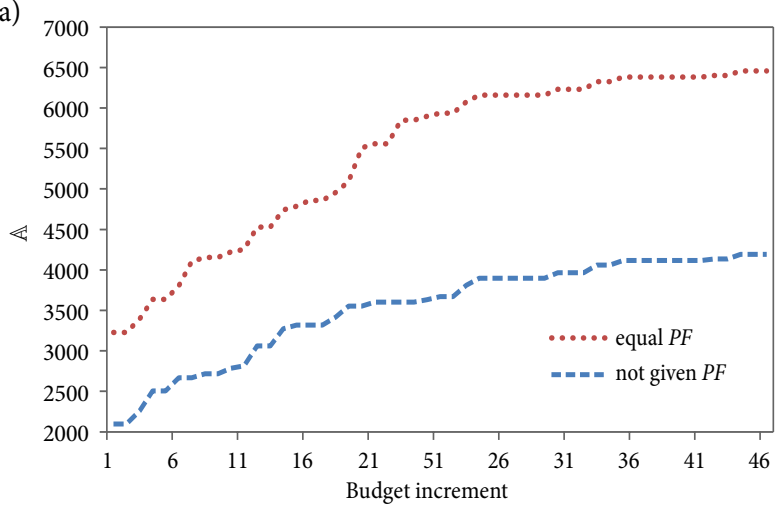

b)

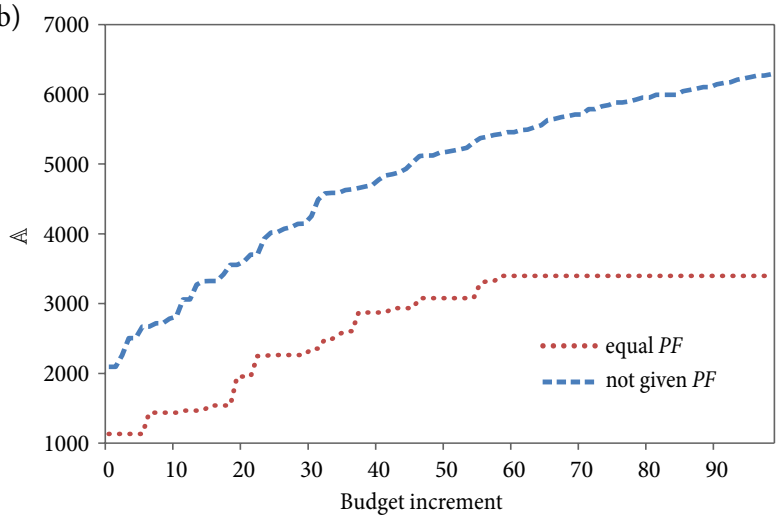

c)

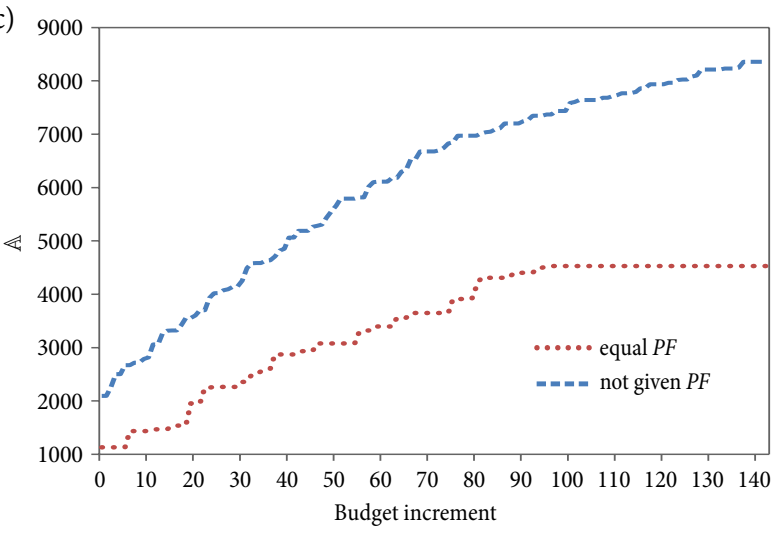

Fig. 6. Absolute capacity versus budget increment:

$$
\mathrm{a}-\|\|_{s}^{\max }=1 ; \mathrm{b}-\|\|_{s}^{\max }=2 ; \mathrm{c}-\|\|_{s}^{\max }=3
$$

\subsection{Time Varying Expansions}

In practice, it is unlikely that the expansion of the RAI railway network can be performed at once, in one go. Hence, the application of the time varying capacity expansion model is necessary. That model was applied in this section. Our analysis first assumes that the track duplication cost is $\$ 100 \mathrm{k}$ per $\mathrm{km}$ of rail, and a budget of say $\$ 100$ million is available, with $\$ 10$ million available each year (i.e. over a period of ten years). These parameters are indicative of real life values but have been chosen by conjecture and estimation. The target capacity is 50 trains. Intermediate capacity requirements are imposed in the following way: $A_{p}=p\left(\frac{A_{F}-A_{I}}{10}\right)$. The time varying model was run for the RAI railway net-

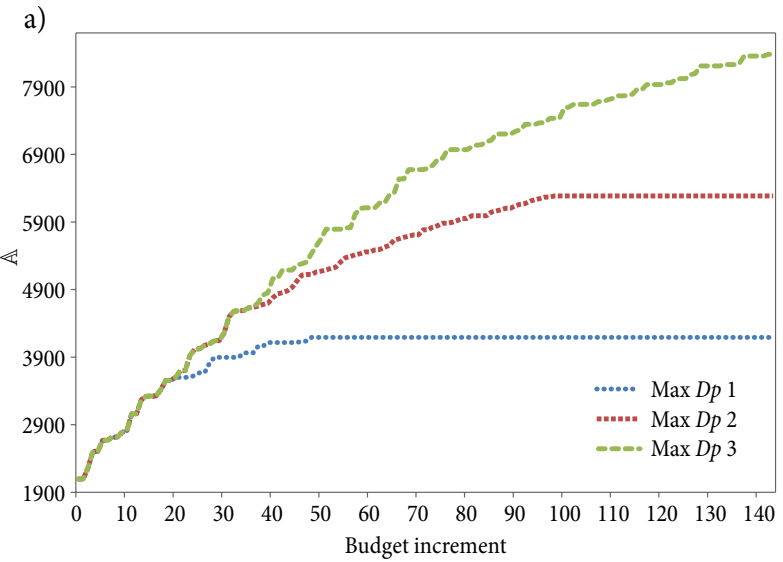

b)

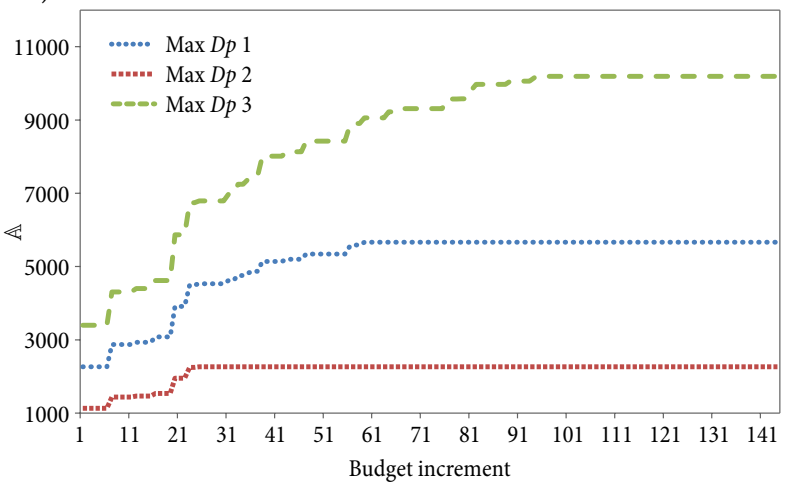

Fig. 7. Absolute capacity by budget increment: a - equal $P F$; b - no restriction on $P F$

work for different limits of the number of duplications in each section. It should be noted that for a maximum of one duplication in each section, the capacity model is infeasible. For example, it is impossible to reach the target capacity. For all other duplication limits, the target capacity was reached in three periods. The solutions are shown in Table 16.

Table 16 shows no distinguishable pattern of cost and expenditure across the different periods. In fact, the same costs and spending were sometimes chosen (i.e. $\left.\|_{s}^{\max }=5,6,9,10\right)$. The expansion plans were compared in order to see whether common sections were duplicat-

Table 16. The expansion results (no restriction on $\%$ flow)

\begin{tabular}{|c|c|c|}
\hline$\|_{s}^{\max }$ & Cost & $E$ \\
\hline 1 & - & - \\
\hline 2 & 2739 & $(990,990,759)$ \\
\hline 3 & 2673 & $(990,990,693)$ \\
\hline 4 & 2937 & $(990,957,990)$ \\
\hline 5 & 2970 & $(990,990,990)$ \\
\hline 6 & 2970 & $(990,990,990)$ \\
\hline 7 & 2310 & $(990,957,363)$ \\
\hline 8 & 2178 & $(957,990,231)$ \\
\hline 9 & 2970 & $(990,990,990)$ \\
\hline 10 & 2970 & $(990,990,990)$ \\
\hline
\end{tabular}


ed, particularly for those duplication limits that resulted in the same total cost and spending. In summary, the results were all different, and the expansion plan is specific in each case. Some of the expansion plans are shown:

\|\|$_{s}^{\max }=2:$

Period 1: $(6,12,13,14,15,16,18,27,29,35,37) \times$ $1+(23) \times 2$;

Period 2: $(2,3,7,11,17,18,22,24,25,26,27,30) \times$ $1+(4,19) \times 2$;

Period 3: $(2,3,9,20,22,30,35,37) \times 1+(5) \times 2$.

\|\|$_{s}^{\max }=3$ :

Period 1: $(6,7,18,23,26,29) \times 1+(2,4,25) \times 2+$ (3) $\times 3$;

Period 2: $(2,4,5,6,25,30) \times 1+(1,19,22,23,24$, 27) $\times 2$;

Period 3: $(7,8,20,21,27,28,29) \times 1+(30) \times 2$. \|\|$_{s}^{\max }=4:$

Period 1: 2(1), 3(1), 4(1), 10(1), 11(1), 12(1), 13(1), 16(1), 17(2), 18(1), 19(1), 29(1), 30(1);

Period 2: 2(1), 3(1), 4(1), 5(1), 6(2), 7(1), 14(1), 15(2), 18(2), 23(1), 30(1);

Period 3: 1(1), 4(2), 8(1), 18(1), 24(1), 29(2), 30(2).

$$
\|_{s}^{\max }=9 \text { : }
$$

Period 1: 2(2), 3(1), 4(2), 5(1), 6(1), 7(1), 18(1), 19(1), 21(1), 22(1), 23(1), 24(1), 25(2), 26(1), 27(2);

Period 2: 3(1), 23(1), 29(2), 30(3);

Period 3: 11(1), 12(1), 13(1), 14(1), 15(1), 16(1), 17(1), 20(1), 22(1), 23(1), 29(1), 30(2).

The expenditure in each period (i.e. $E$ ) is shown in Tables $16-17 . E$ is defined in units of $\$ 1000$. The section that was duplicated in each period (i.e. $S$ ) is also shown in Fig. 8. After 3 periods no more expansion occurs and

Table 17. The plan of expansion activity considering inflation

\begin{tabular}{|c|c|c|c|c|c|c|}
\hline & \multicolumn{2}{|r|}{\|\|$_{s}^{\max }=2$} & \multicolumn{2}{|c|}{$\|_{s}^{\max }=3$} & \multicolumn{2}{|c|}{$\|_{s}^{\max }=10$} \\
\hline$P$ & $E$ & $S$ & $E$ & $S$ & E & $S$ \\
\hline 1 & 140 & 20 & 0 & - & 0 & - \\
\hline 2 & 927 & $2,3,4,18$ & 927 & $2,3,4,18$ & 927 & $2,3,4,18$ \\
\hline 3 & 954 & $4,6,7,18,27$ & 954 & $4,6,10,21,22$ & 954 & $3,5,6,7,22,23$ \\
\hline 4 & 981 & $2,21,23,25$ & 981 & $5,13,22,23,27$ & 981 & $3,4,19,23,25$ \\
\hline 5 & 980 & $3,5,6,10,14,26,28$ & 980 & $3,7,24,25,26,28$ & 952 & $1,2,8,24,26,27$ \\
\hline 6 & 943 & $12,13,17,22,24,27$ & 989 & $2,19,20,23,24,27$ & 644 & $2,4,6$ \\
\hline 7 & 826 & $11,15,16,19,24$ & - & - & - & - \\
\hline
\end{tabular}

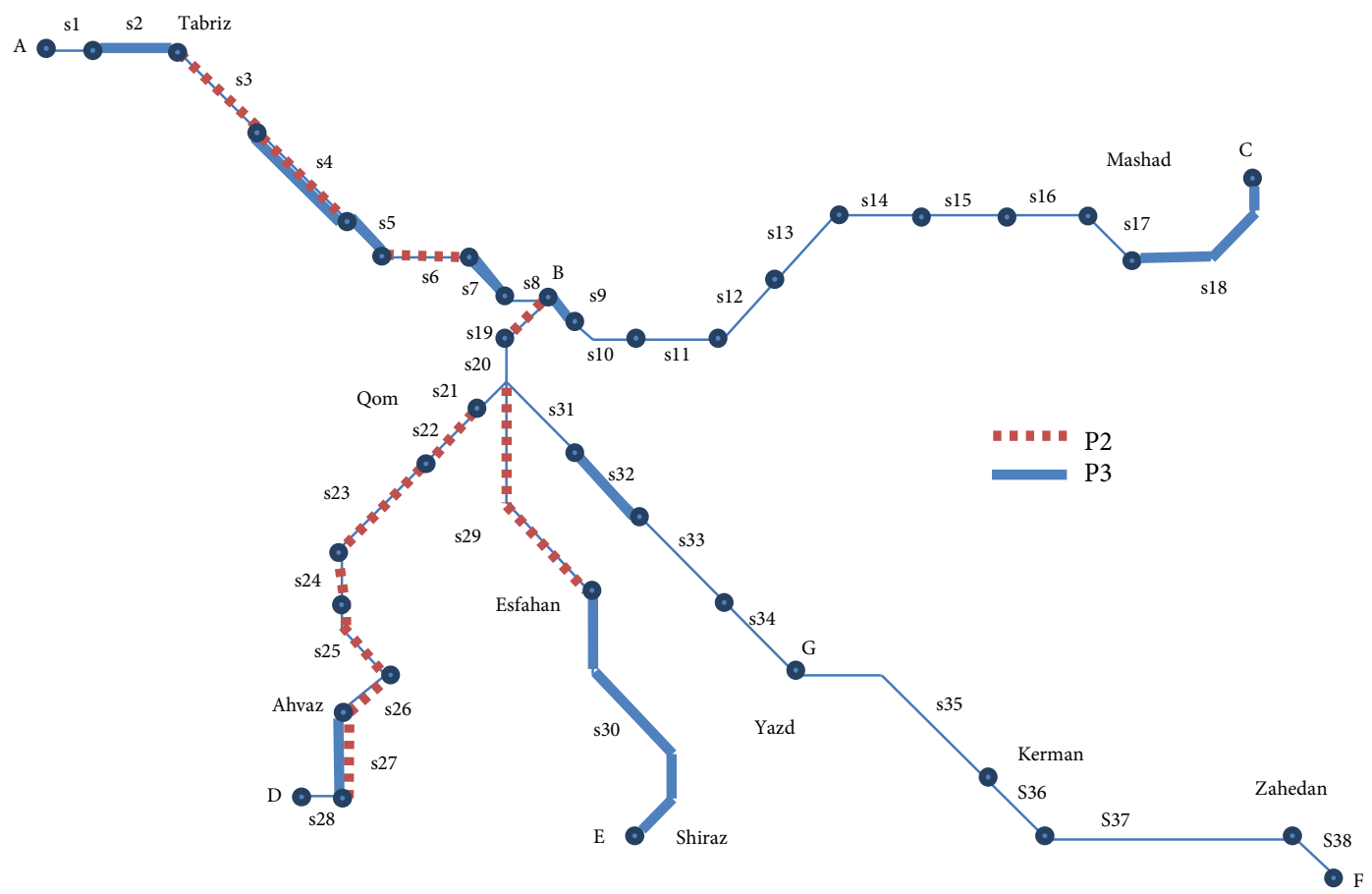

Fig. 8. The plan of expansion activity over time for $\|_{s}^{\max }=2$ 
there is no more spending. It should be noted that the results in Tables 16 and 17 consider a fixed intermediate absolute capacity over ten periods, which are: [2059, 2647.2, 2941.3, 3235.4, 3529.5, 3823.6, 4117.7, 4411.8, $4705.9,5000]$.

The price of infrastructure changes from year to year due to inflation and other economic forces. Incorporating inflation in the model is very useful and practical and a more realistic plan can be generated. The time varying model could address this possibility by adding a 3\% increase to track duplication costs from period to period (i.e. $\left.C t_{(s, p+1)}^{\|}=C t_{(s, p)}^{\|} \cdot 1.03\right)$. Table 17 shows that the target capacity is reached in 6 periods and also expenses are increased.

\section{Conclusions}

In this article, analytical models have been used to analyse the capacity of the National Iranian Rail network. How to perform a sensitivity analysis to facilitate a more in depth analysis of capacity has also been demonstrated. The analytical models were solved numerous times as part of that analysis. The sensitivity analysis was necessary because railway capacity is not a single value. Typically, the solution of the model is a single value and this is not representative of all possibilities in practice.

In this paper, we have also proposed a track duplication component for the capacity model. In practice, capacity expansion is normally a manual task performed by consultants and requires the establishment of a set of permissible expansion scenarios. In this paper, we have compared that manual task to our automated model. The new method has been motivated by the difficulty of performing capacity expansion by hand.

The numerical investigations of the RAI network have shown that corridor $\mathrm{A}-\mathrm{C}, \mathrm{A}-\mathrm{D}$, and $\mathrm{C}-\mathrm{D}$ have the highest capacity and this is clearly obvious from the network diagram. For example, those corridors have a greater number of smaller sections; this allows more traffic to flow. In practice, those three corridors constitute the paths with the highest passenger and freight demand.

Capacity expansion of this network was then explored and an iterative process was then proposed as a preliminary technique. While successful, this approach does not guarantee an optimal plan of expansion activities. Hence, this paper has demonstrated a need for some formal model extensions such as track duplication, capacity expansion, etc. These extensions are necessary in order to speed up the analysis process, and to provide an autonomous process, as opposed to a manual process whereby an analyst has to alter various parameters and to define different cases.

Static and time varying model were formulated and applied. The proposed model could be used to help planners increase the capacity over a specified time; the model can easily assess different budgets and costs in each period. The static model was introduced to identify the best sections to duplicate immediately to obtain the maximum capacity. The time varying model determines a plan over time and can consider things like inflation. A sensitivity analysis of the model was performed for specified limitation on the maximum number of duplications in each section. The expansion model can include other costs such as the cost of earth works and it is quite robust and generic.

\section{References}

Bevrani, B.; Burdett, R.; Yarlagadda, P. K. D. V. 2015. A sensitivity analysis of train speed and its effect on railway capacity, Advanced Materials Research 1061-1062: 1208-1212. http://dx.doi.org/10.4028/www.scientific.net/AMR.10611062.1208

Burdett, R. L.; Kozan, E. 2014. Determining operations affected by delay in predictive train timetables, Computers \& Operations Research 41: 150-166.

http://dx.doi.org/10.1016/j.cor.2013.08.011

Burdett, R. L.; Kozan, E. 2006. Techniques for absolute capacity determination in railways, Transportation Research Part B: Methodological 40(8): 616-632.

http://dx.doi.org/10.1016/j.trb.2005.09.004

Burdett, R. L.; Kozan, E. 2004. Absolute capacity determination and timetabling in railways, in Proceedings of the Fifth Asia Pacific Industrial Engineering and Management Systems Conference 2004 (APIEMS 2004), 12-15 December 2004, Gold Coast, Australia, 30.1.1-30.1.16.

Burdett, R. L.; Kozan, E. 2003. Resource aggregation issues and effects in mixed model assembly, in E. Kozan, R. Beard, G. Chattopadhyay (Eds.). Proceedings 5th Operations Research Conference of the Australian Society for Operations Research Queensland Branch on Operations Research into the 21st Century, 9-10 May 2003, Sunshine Coast, Australia, 35-53.

De Kort, A. F.; Heidergott, B.; Ayhan, H. 2003. A probabilistic $(\max ,+)$ approach for determining railway infrastructure capacity, European Journal of Operational Research 148(3): 644-661. http://dx.doi.org/10.1016/S0377-2217(02)00467-8

Dingler, M.; Lai, Y.-C.; Barkan, C. 2009. Impact of train type heterogeneity on single-track railway capacity, Transportation Research Record: Journal of the Transportation Research Board 2117: 41-49. http://dx.doi.org/10.3141/2117-06

Ferguson, J. M. 2014. Asymptotic Accuracy of the Equilibrium Diffusion Approximation and Semi-analytic Solutions of Radiating Shocks: PhD dissertation. Texas A\&M University. 202 p. Available from Internet: http://hdl.handle. net/1969.1/152454

Gibson, S. 2003. Allocation of capacity in the rail industry, Utilities Policy 11(1): 39-42. http://dx.doi.org/10.1016/S0957-1787(02)00055-3

Goverde, R. M. P.; Corman, F.; D’Ariano, A. 2013. Railway line capacity consumption of different railway signalling systems under scheduled and disturbed conditions, Journal of Rail Transport Planning \& Management 3(3): 78-94. http://dx.doi.org/10.1016/j.jrtpm.2013.12.001

Harrod, S. 2009. Capacity factors of a mixed speed railway network, Transportation Research Part E: Logistics and Transportation Review 45(5): 830-841. http://dx.doi.org/10.1016/j.tre.2009.03.004

IranRail. 2014. The Unofficial Homepage of Iranian Railways. Trains. Iran. Available from Internet: http://www.iranrail. net

Jim Fergusson's Railway and Tramway Station Lists. 2014. Available from Internet: http://www.railwaystationlists.co.uk 
Kozan, E.; Burdett, R. 2005. A railway capacity determination model and rail access charging methodologies, Transportation Planning and Technology 28(1): 27-45.

http://dx.doi.org/10.1080/0308106052000340378

Khajehpour, B. 2013. Iran's crisis on the roads, Al-Monitor: the Pulse of the Middle East. Available from Internet: http:// www.al-monitor.com/pulse/originals/2013/11/iran-trafficdeaths-crisis-roads.html

Krueger, H. 1999. Parametric modeling in rail capacity planning, in 1999 Winter Simulation Conference Proceedings, 5-8 December 1999, Phoenix, AZ, 2: 1194-1200. http://dx.doi.org/10.1109/WSC.1999.816840

Lai, Y.-C.; Shih, M.-C.; Jong, J.-C. 2010. Railway capacity model and decision support process for strategic capacity planning, Transportation Research Record: Journal of the Transportation Research Board 2197: 19-28. http://dx.doi.org/10.3141/2197-03

Lai, Y.-C.; Barkan, C. P. L. 2011. Comprehensive decision support framework for strategic railway capacity planning, Journal of Transportation Engineering 137(10): 738-749. http://dx.doi.org/10.1061/(ASCE)TE.1943-5436.0000248

Landex, A. 2009. Evaluation of railway networks with single track operation using the UIC 406 capacity method, Networks and Spatial Economics 9(1): 7-23.

http://dx.doi.org/10.1007/s11067-008-9090-7

Lusby, R. M.; Larsen, J.; Ehrgott, M.; Ryan, D. 2011. Railway track allocation: models and methods, OR Spectrum 33(4): 843-883. http://dx.doi.org/10.1007/s00291-009-0189-0

Mussone, L.; Wolfler Calvo, R. 2013. An analytical approach to calculate the capacity of a railway system, European Journal of Operational Research 228(1): 11-23. http://dx.doi.org/10.1016/j.ejor.2012.12.027

Shih, M.-C.; Dick, C. T.; Sogin, S. L.; Barkan, C. P. L. 2014. Comparison of capacity expansion strategies for singletrack railway lines with sparse sidings, Transportation Research Record: Journal of the Transportation Research Board 2448: 53-61. http://dx.doi.org/10.3141/2448-07

Singh, G.; Sier, D.; Ernst, A. T.; Gavriliouk, O.; Oyston, R.; Giles, T.; Welgama, P. 2012. A mixed integer programming model for long term capacity expansion planning: a case study from The Hunter Valley Coal Chain, European Journal of Operational Research 220(1): 210-224.

http://dx.doi.org/10.1016/j.ejor.2012.01.012

Tehran Times. 2012. Iran to Extend Rail Network to 15000 Kilometers by 2015. Available from Internet: http://www. tehrantimes.com

UIC. 2004. UIC Code 406 R: Capacity. International Union of Railways (UIC). 26 p.

Vromans, M. J. C. M.; Dekker, R.; Kroon, L. G. 2006. Reliability and heterogeneity of railway services, European Journal of Operational Research 172(2): 647-665.

http://dx.doi.org/10.1016/j.ejor.2004.10.010

Yaghini, M.; Nikoo, N.; Ahadi, H. R. 2014. An integer programming model for analysing impacts of different train types on railway line capacity, Transport 29(1): 28-35. http://dx.doi.org/10.3846/16484142.2014.894938

\section{APPENDIX A}

Table A1. Network data

\begin{tabular}{|c|c|c|c|}
\hline$\#$ & Corridor & \# section & Length $[\mathrm{km}]$ \\
\hline 1 & A-C & 20 & 2550 \\
\hline 2 & A-D & 18 & 2295 \\
\hline 3 & A-E & 16 & 2320 \\
\hline 4 & A-F & 18 & 3165 \\
\hline 5 & C-D & 22 & 2625 \\
\hline 6 & C-E & 20 & 2650 \\
\hline 7 & C-F & 22 & 3495 \\
\hline 8 & D-E & 14 & 1995 \\
\hline 9 & D-F & 16 & 2840 \\
\hline
\end{tabular}

Table A2. Section information (i.e. lengths)

\begin{tabular}{|c|c|c|c|c|c|c|c|}
\hline$\#$ & $L$ & $\#$ & $L$ & $\#$ & $L$ & $\#$ & $L$ \\
\hline 1 & 75 & 12 & 150 & 23 & 200 & 34 & 210 \\
\hline 2 & 190 & 13 & 110 & 24 & 120 & 35 & 420 \\
\hline 3 & 210 & 14 & 150 & 25 & 140 & 36 & 150 \\
\hline 4 & 220 & 15 & 150 & 26 & 100 & 37 & 450 \\
\hline 5 & 100 & 16 & 150 & 27 & 150 & 38 & 100 \\
\hline 6 & 150 & 17 & 150 & 28 & 65 & & \\
\hline 7 & 100 & 18 & 280 & 29 & 440 & & \\
\hline 8 & 65 & 19 & 130 & 30 & 570 & & \\
\hline 9 & 50 & 20 & 70 & 31 & 165 & & \\
\hline 10 & 100 & 21 & 70 & 32 & 150 & & \\
\hline 11 & 150 & 22 & 140 & 33 & 210 & & \\
\hline
\end{tabular}

\section{APPENDIX B}

The following mix of trains was investigated:

$\eta=[[0.0,0.44,0.56],[0.31,0.45,0.24],[0.86,0.14,0.0]$, $[0.87,0.1,0.03],[0.39,0.26,0.35],[0.49,0.36,0.15]$,

$[0.0,0.44,0.56],[0.31,0.45,0.24],[0.86,0.14,0.0]]$. 